Article

\title{
Dimensions of Customer Value for the Development of Digital Customization in the Clothing Industry
}

\author{
Wen-Jie Yan ${ }^{1,2, *(1)}$ and Shang-Chia Chiou ${ }^{1}$ \\ 1 Graduate School of Design, National Yunlin University of Science and Technology, Yunlin 64002, Taiwan; \\ chiousc@yuntech.edu.tw \\ 2 Fujian Key Laboratory of Novel Functional Textile Fibers and Materials, Minjiang University, \\ Fuzhou 350108, China \\ * Correspondence: yanwenjie2003@gmail.com
}

Received: 16 April 2020; Accepted: 3 June 2020; Published: 5 June 2020

\begin{abstract}
Triggered by the rapid development of digital technology, Chinese clothing manufacturers have begun to provide digital customization for clothing. The digital transformation of clothing customization provides new opportunities to meet customers' personalized needs and optimize production resources, and facilitates the sustainable development of the clothing customization industry. This study constructed dimensions of customer value in clothing customization, based on the development of the industry under digital technology. The research was divided into two phases: the first phase involved establishing customer value indicators through expert interviews, questionnaire design, and statistical analyses in SPSS; and the second stage involved the expert group conducting a consumer experience evaluation of a digital customization platform. Thirty customer value indicators were extracted and four dimensions were established: authenticity value, social value, aesthetic value, and utility value. The results of the study show that the value demands of Chinese consumers for apparel customization have shifted to perceptible authenticity values (service, experience, content). The four customer value dimensions proposed by this research can be used to evaluate customer value in digital customization consumption models.
\end{abstract}

Keywords: customer value; sustainable development; digital technologies; clothing customization

\section{Introduction}

From the industrial age to the Internet age and the current digital age, old business models have been overturned, with new business models constantly being introduced. Chinese consumers have been highly digitized in their consumption, work, life, learning, and entertainment behaviors, and have begun to pursue differentiated and customized products and services. Digital consumption, digital production, digital interaction, and digital collaboration are the keywords of today. Clothing companies that think digitally recognize that providing digital services can bring new social and commercial value to brands. Digital personalized customization is the manifestation of the transition from traditional manufacturing to intelligent manufacturing. Its essence is to use the Internet platform and smart factory construction to directly convert user needs into production plans. Customized production users not only appear at both ends of the production process, but can also participate extensively in the entire production process and in value creation. However, achieving personal customization is a long and arduous process.

At present, the literature on clothing customization and customer value under digital technology is limited. Research on digital clothing customization has mainly focused on digital service technology and business models. Among the research, the existing service technology research has mainly concentrated on the fields of 3D scanning technology, intelligent clothing platemaking, and network integration platforms. Little research has investigated the key players (users, or customers) in clothing customization. 
In this study, based on the customer value theory, a questionnaire-based survey was conducted on the users (consumers) of Chinese men's clothing digital customization platforms to explore the factors that affect the perception of customer value in clothing customization and build a customer value dimension. This study not only extends the literature on the customer value of clothing customization under digital technology but also provides data for understanding the sustainable development of China's clothing customization consumer market. The implementation process used in this study is shown in Figure 1.

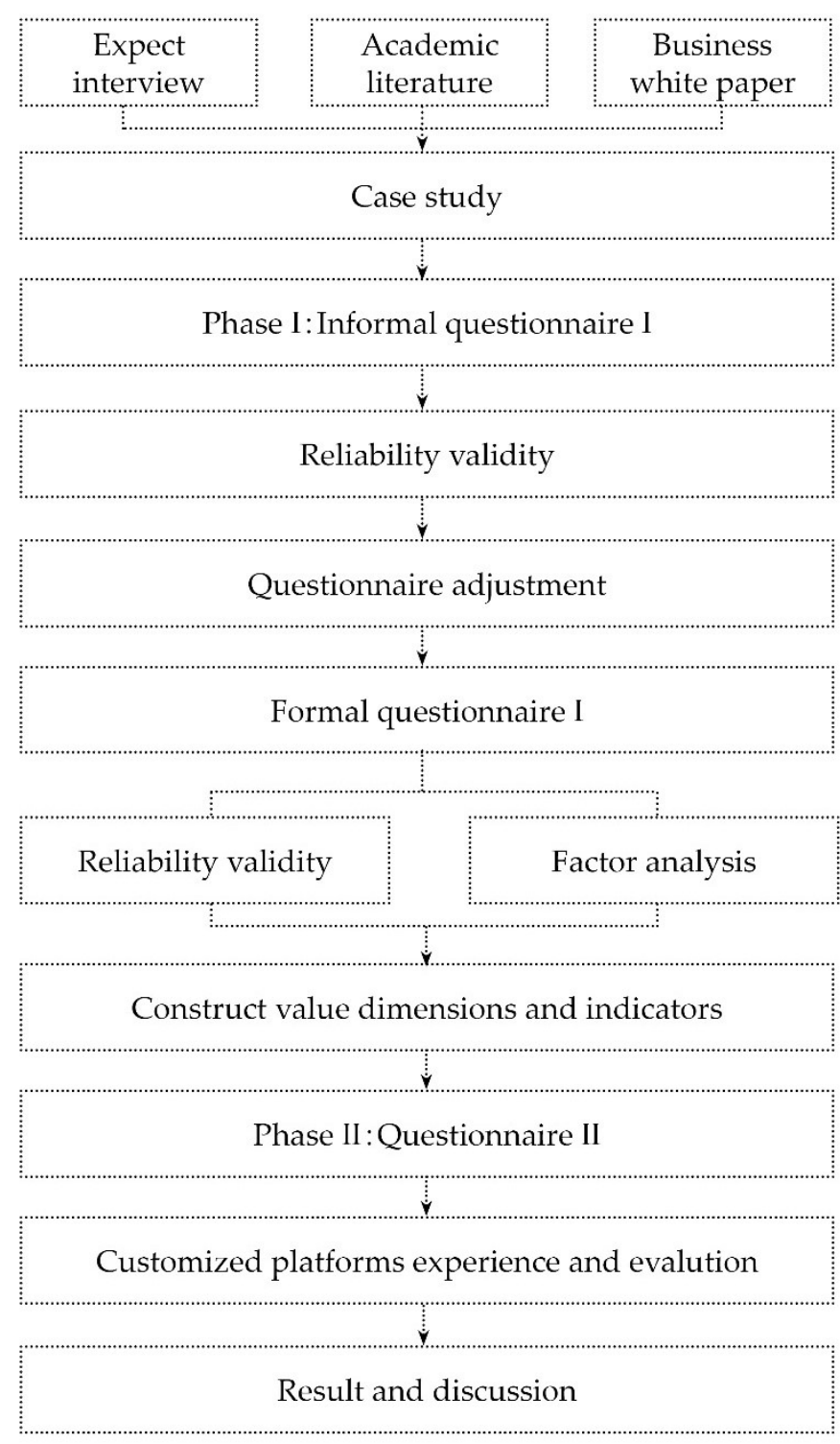

Figure 1. Research process.

In this article, we review the transformation of China's clothing manufacturing industry and the challenge of customized production under the influence of digital technology, consumption upgrading, and national policies. We further describe the status of clothing digital technology applications and current literature on customer value in the clothing industry. The description of the study is divided into two phases: Phase I involved a case study that allowed for the definition of an initial questionnaire I method to converge the indicators of customer value. Phase II detailed an optimized questionnaire II to evaluate the performance of customer value indicators on the digital customization platform. Finally, we present a summary and discussion of the combined results from Phases I and II. 


\section{Literature Review}

As Gilmore and Pine [1] proposed, "commodities are just the material carriers of the services they provide; services are only the intangible operations of the experience they show, and experience is just an unforgettable event leading to transformation." In this analysis, while the supply-side manufacturer meets the demand-side consumer's personalized customization requirements for clothing, the demand-side consumption triggers new consumption in return, thereby bringing about the sustainable development of customized production. This requires no intermediary markup, no backlog of funds and goods, and a reduction in corporate costs. There is no need for consumers to share the costs of circulation and inventory as they would under the traditional retail model. Furthermore, they derive creative enjoyment from participating directly in the production of their clothing. This scenario could yield considerable profit margins for manufacturers and is a result of the consumer's demand that companies continue to carry out technological innovation.

While upgrading digital technology, manufacturers and brands may be able to play a role in guiding consumers to rational consumption and sustainable fashion. Eventually, the focus of attention may shift from consumer rights to human rights, and ultimately the true customer value. Papanek [2] put forth the idea of design for people's genuine needs, rather than to meet evanescent wants and desires. Here, design must be related to the real needs of consumers and be ecologically responsible. Therefore, clothing customization facilitated by digital technology should not be a tool to stimulate increased consumption but should provide a bridge between a consumer's real individual needs and mass production.

\subsection{Sustainable Development of Clothing under Digital Technology}

Science and technology and commerce have always developed in tandem, promoting, and restricting one another. The increasing complexity of businesses has driven the continuous upgrading and migration of digital technology. Digital technology-related vocabulary, such as big data, blockchain, artificial intelligence, smart factories, smart manufacturing, industry 4.0, the Internet of Things, and digital twins, is increasingly flooding people's daily lives and digital technology is restructuring and updating all industries. In China's clothing industry, digital technologies such as CAD (Computer-Aided Design), ERP (Enterprise Resource Planning), 3D scanning, MTM (Made to Measure), and virtual fitting are driving the digitalization of production management, goods, and consumption [3].

Digital clothing customization is based on traditional clothing customization and ready-to-wear production. It provides consumers with digital clothing customization solutions. Fashion retailers using new interactive digital technology formats (online and offline retail, including new hybrid environments) can increase customer engagement in shopping [4]. Properly driven digital transformation can reshape the fashion industry into a more sustainable and truly customer-oriented business [5]. Digital sales and manufacturing, as well as circular value networks, can contribute to business models that support sustainable development in the textile and apparel industries [6]. Digital customization meets the requirements of comfort, while at the same time allowing industrialized mass production and more competitive pricing. China has a large number of young Internet users, creating conditions for the rapid commercial use of new digital business models. The demand side and supply side of Chinese clothing customization rely on the convenience provided by digitalization to create co-creation value (see Figure 2).

As the clothing manufacturing industry moves towards sustainable development, the industry is facing the challenges of harnessing digital technology and transforming towards a customized production model. In customer relationship management research, the discussion of customer value has always been at the core of commercial marketing. Therefore, the construction of the dimensions of customer value in the digital customization of clothing will facilitate the garment manufacturing industry to move towards sustainable customized production and accurate marketing. 


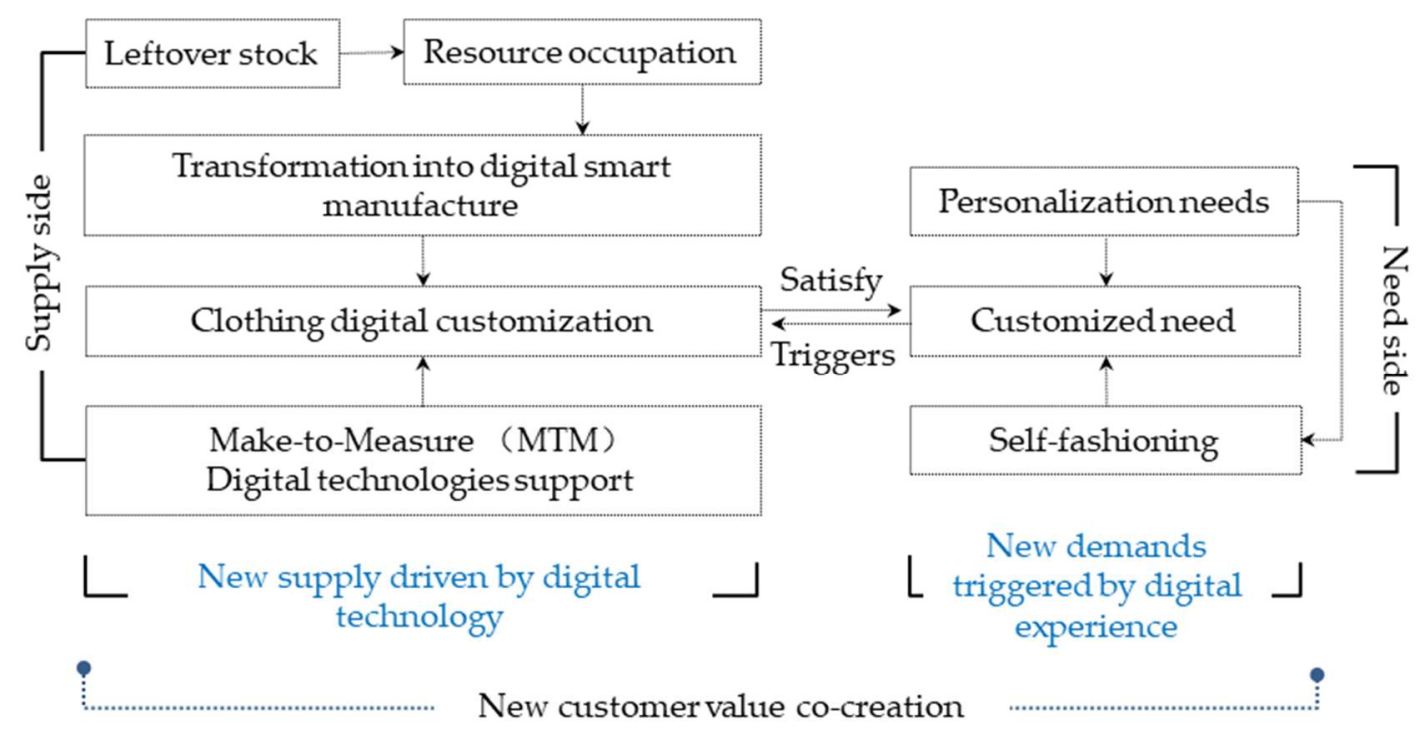

Figure 2. Customized production and consumption in the digital economy. Source: Figure developed by the authors.

\subsection{Customer Value in Clothing Digital Customization}

From the perspective of the retail industry, all retail goods must convey the value of the products to the consumers. Value perceived by consumers determines what a good product is. Understanding the value that customers expect and continuously providing that value has become a key element of success in the marketplace [7].

Different studies have offered varying criteria for the basic elements of customer value. Duchessi [7] proposed a complete customer value framework (CVF) to explain the operating principles of customer value in the contexts of business systems, personnel systems, quality systems, and information systems. Focusing on durable products, Kantameni and Coulson's [8] research argued that customer value arose from four aspects: functional value, market value, experience value, and social value. Smith and Colgate [9] summarized the previous literature, classifying customer value into the following four types: function/tool value, symbol/performance value, experience/hedonic value, and cost/sacrifice value. Sheth [10] explored the reasons for customer purchases, arguing that customers' willingness to consume was determined mainly by five dimensions of customer value: (1) social value, which indicated product utility; (2) functional value, which indicated product attributes; (3) known value, which indicated the attractiveness of the product; (4) emotional value, which referred to the ability of the product to resonate with customer emotions; and (5) environmental value, which referred to the product's social impact. The customer's value confirmation was said to be considerably affected by the restrictions in the special use situation; the judgment was limited by various use situations and time, and it will be subject to the agitation of the "triggers" situation [11]. The idea of customer value as a function of cognitive and emotional activity is thus constantly changing and developing.

Scholars have also taken different approaches to study customer value in the context of clothing customization. $\mathrm{Wu}$ and $\mathrm{Su}$ [12] limited the research to the network element of the "consumer-toconsumer" environment, arguing that the perceived value of customers' online purchases was mainly a function of the products' quality and price, the associated services (online communication and logistics transportation), the website's ease of use, and protection of privacy. Zhao, Shan, and Liu [13] studied the trust of online consumers, proposing the classification of customer value according to emotional value, experiential value, and economic value. Peng [14] posited that, based on the operation mechanism of the digital customization model around the theme of customer perceived value, the factors that affected brand loyalty were experience, functionality, sociality, economy, individualization, intelligence, and branding. Li and $\mathrm{Zhu}$ [15] conducted a questionnaire survey on $\mathrm{O} 2 \mathrm{O}$ clothing custom brands, based 
on the theory of customer perceived value. From this, they extracted the four dimensions of customer perceived value: emotion value, social value, quality value, and price value. The key point of clothing customization was quality. Zhu and Wei [16], through statistical analyses, concluded that the experience of functionality, service, personalization, and hedonism in different situations would positively affect the experience value of consumers, and sociality and after-sales service would also have a positive impact on the relaxed experience. Hong and Zhu [17] presented value evaluation indicators for the spirit of clothing customization craftsmen, that is, products, services, brands, personnel, and facilities. In sum, the present study is based on the premise that the core customer value for implementing digital clothing customization is make-to-measure. Digital clothing customization involves using individual digital information technologies in the process of designing, providing, and experiencing clothing to provide customers with a complete set of clothing design solutions.

Studies have put forward different theoretical models of customer value from different perspectives $[18,19]$. In the dynamic research field of customer value, the focus lies on the dynamic characteristics of customer value and the "trigger events" of customer value change [20-24]. Although many researchers agree that customer value needs to be studied dynamically, there is little empirical research on customer value. The defects of the existing research lie in the narrow research background and the lack of theoretical research on emerging formats.

Most researchers use quantitative research methods [25-27] to investigate customer value in clothing customization, while there is also some discussion of the value philosophy of customization [28]. Therefore, this study discusses the theory of customer value in the clothing customization production triggered by emerging technology (digital technology). The results of this current study will be conducive to guiding the theory and practice of sustainable clothing customization, production, and marketing.
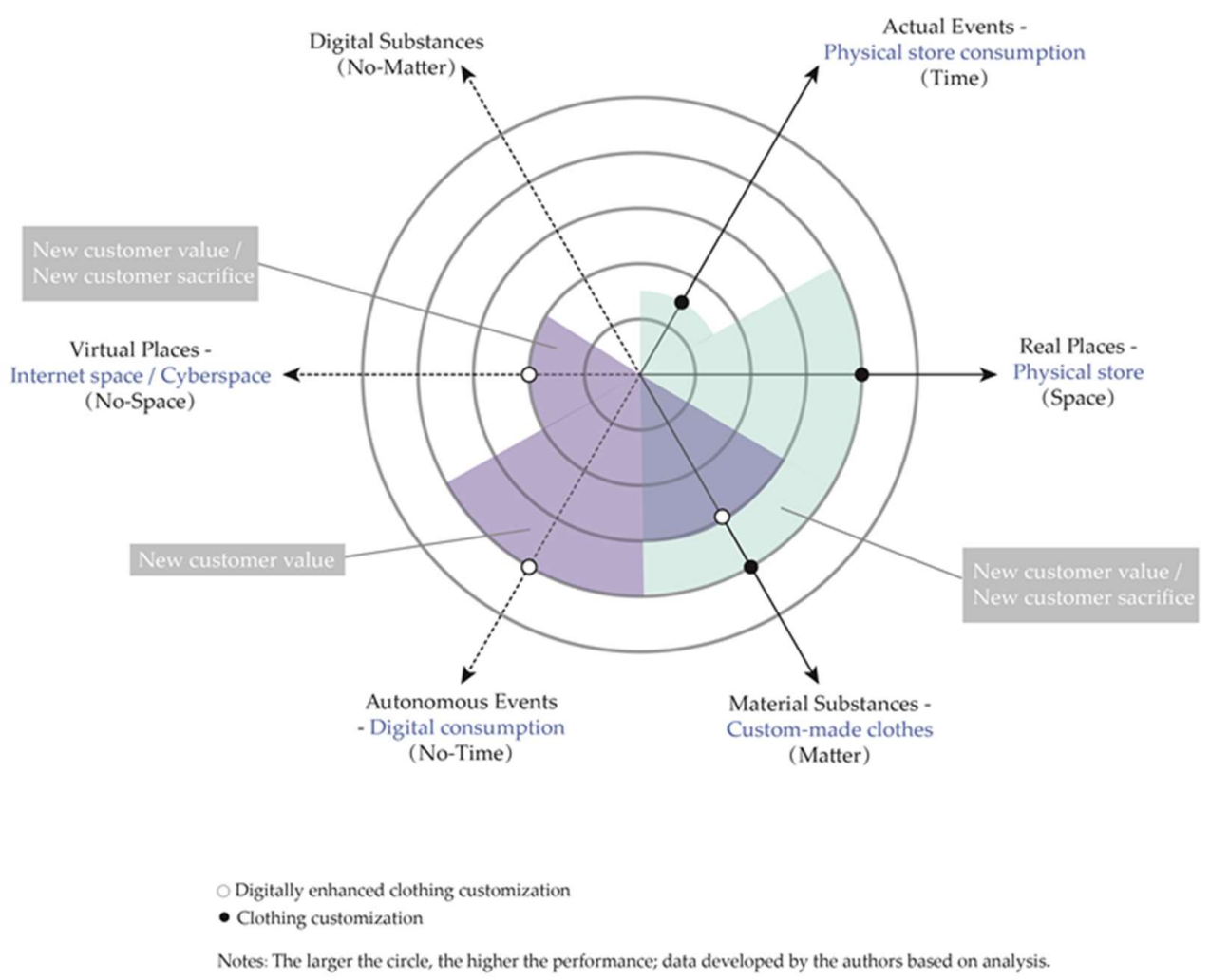

Figure 3. Change in perceived consumer value of clothing customization in the digital economy. Source: Figure adapted and adjusted from Pine and Korn, 2011 [29].

Pine II and Korn [29] put forward the framework of a multiverse, using "time, no time, space, no space, matter, and no matter" as the six variables to describe how experiences happen. Here, according to the framework of the multiverse, we describe the change of perceived value in the 
consumption experience of clothing customization in the digital economy (Figure 3). In the space of digital consumption and physical consumption, new customer value will increase or decrease new customer sacrifice. Customer satisfaction is the difference between what a customer wants, and what they settle for [29]. In the dimension of "time", digital customization shows its advantages and produces new customer value; in the dimension of "space", it brings about new consumer experiences (this is new customer value, accompanied by new customer sacrifice); in the dimension of "substances", the gap between customized production clothing and customized store clothing is narrowing. We believe that, through the iteration of digital technology, new customer sacrifice will gradually decrease. The starting point of this study is to reduce customer sacrifice and take clothing as both a product and a representation of self-fashioning. This study aims to explore the latent new customer value indicators in the digital customization of the clothing consumption experience, to guide the sustainable development of clothing customization marketing practice.

\section{Phase I: Customer Value Survey in Clothing Customization}

As the first part of the research design, Phase I involved the extraction of customer value indicators. The implementation of customer value variables was divided into two stages. First, a case study was used to amass indicators from three divisions of the literature: business white papers, academic literature, and expert interviews. Secondly, the indicators were converted to form a questionnaire. Finally, the results of the questionnaire were interrogated using factor analysis to obtain customer value indicators. The significant factors in questionnaire 1 after the convergence of factors were carried into Phase II.

\subsection{Case Study}

\subsubsection{Expert Interviews}

Expert interviews allow for the collection of qualitative data. Expert selection is based on purposive sampling, which is a common method in qualitative research. Qualitative research focuses on the content of information materials and its purpose is to maximize information, rather than facilitate statistical inference. This research established consumer questionnaire items through expert interviews. Semi-structured interviews with the expert group were completed from 20 to 24 October 2019. The topic of the interview was the perceived value of customers in digital intelligent clothing customization. Therefore, the interviewees were limited to practitioners related to the clothing industry, including operators of digital intelligent clothing customization brands. The interviewees were six experts, ranging from 30 to 45 years old. Three of the interviewees' jobs were related to the clothing customization business, whereas the other interviewees worked in the design field. These participants were deemed by the researchers to be able to provide professional insight for this research.

The interviews were conducted using WeChat (Wechat is a free application launched by Tencent to provide instant messaging services for smart terminals) and lasted about 40 to $120 \mathrm{~min}$. The outline of the interview was based on the previous research and designed to encourage in-depth conversation between the interviewee and the researcher about the research topic. This in-depth interview focused on how digital clothing customization could better provide customer value and stimulated discussion on the industry development of smart clothing customization and sustainable clothing brand development.

The outline of the interview is shown in Table 1.

The summarized interview results were as follows:

- Customized consumption of clothing should provide practical personal image solutions, and customized clothing should be able to beautify the personal image of consumers.

- The Internet clothing customization platform needs to provide sufficient product details, pictures, and text descriptions, as well as real-time data on the order manufacturing progress that can be queried.

- Manual customer service is indispensable. Customer service personnel should have professional knowledge of clothing customization and provide courteous and timely services. 
- Brand fabrics, fashionable styles, reasonable pricing, and customer data security are the main focus for clothing customization customers.

In general, the higher the interviewee's level in the clothing profession, the more attention was paid to smart clothing customization and the finer the division of value was. Interviewees expected that the Internet customization platform could provide more choices of categories and provide better information security.

Table 1. Expert interview outline.

\begin{tabular}{ll}
\hline \multicolumn{1}{c}{ Purpose of Question } & \multicolumn{1}{c}{ Question } \\
\hline Consumer expertise & $\begin{array}{l}\text { Compared with traditional clothing customization, what kind of } \\
\text { customization experience does digital intelligent clothing customization } \\
\text { need to provide to consumers? }\end{array}$ \\
\hline New customer value & $\begin{array}{l}\text { In your opinion, what is the customer value perceived by consumers in } \\
\text { clothing customization consumption under the digital intelligent } \\
\text { clothing customization model? }\end{array}$ \\
\hline $\begin{array}{l}\text { Approaches to sustainable } \\
\text { industry development }\end{array}$ & $\begin{array}{l}\text { How should the Internet clothing customization brand guarantee the } \\
\text { level of customized service to achieve the purpose of acquiring new } \\
\text { customers and buying again? }\end{array}$ \\
\hline
\end{tabular}

Source: Table developed by the authors based on analysis.

\subsubsection{Business White Paper}

This study selected the business report of China's e-commerce garment industry dynamics as the research text. The relevant factors that influence consumers' purchasing motives and value perception were extracted from the annual reports [30-39] on consumer trends and clothing industry in China's clothing customization industry (Table 2).

\subsubsection{Economic Theory Related to Customer Value}

This study also reviewed the literature on consumer management academic theories [39-47], including the Technology Acceptance Model (TAM), Expectation Confirmation Theory (ECT), Theory of Impression Management (TIM), Circle of Culture, Total Quality Management (TQM), Economics and Culture, and Experience Economy. Appropriate variables (Table 3) related to customer value perception in apparel customization discussed in this study were extracted from the literature [40-47].

\subsection{Construction of Customer Value Indicators}

This study extracted 30 variables related to customer value (Figure 4), from which a questionnaire was designed. Each variable represented the factors that influenced customers' experiences in clothing customization (Table 4). 
Table 2. Business white paper: indicators and sources for the study variables.

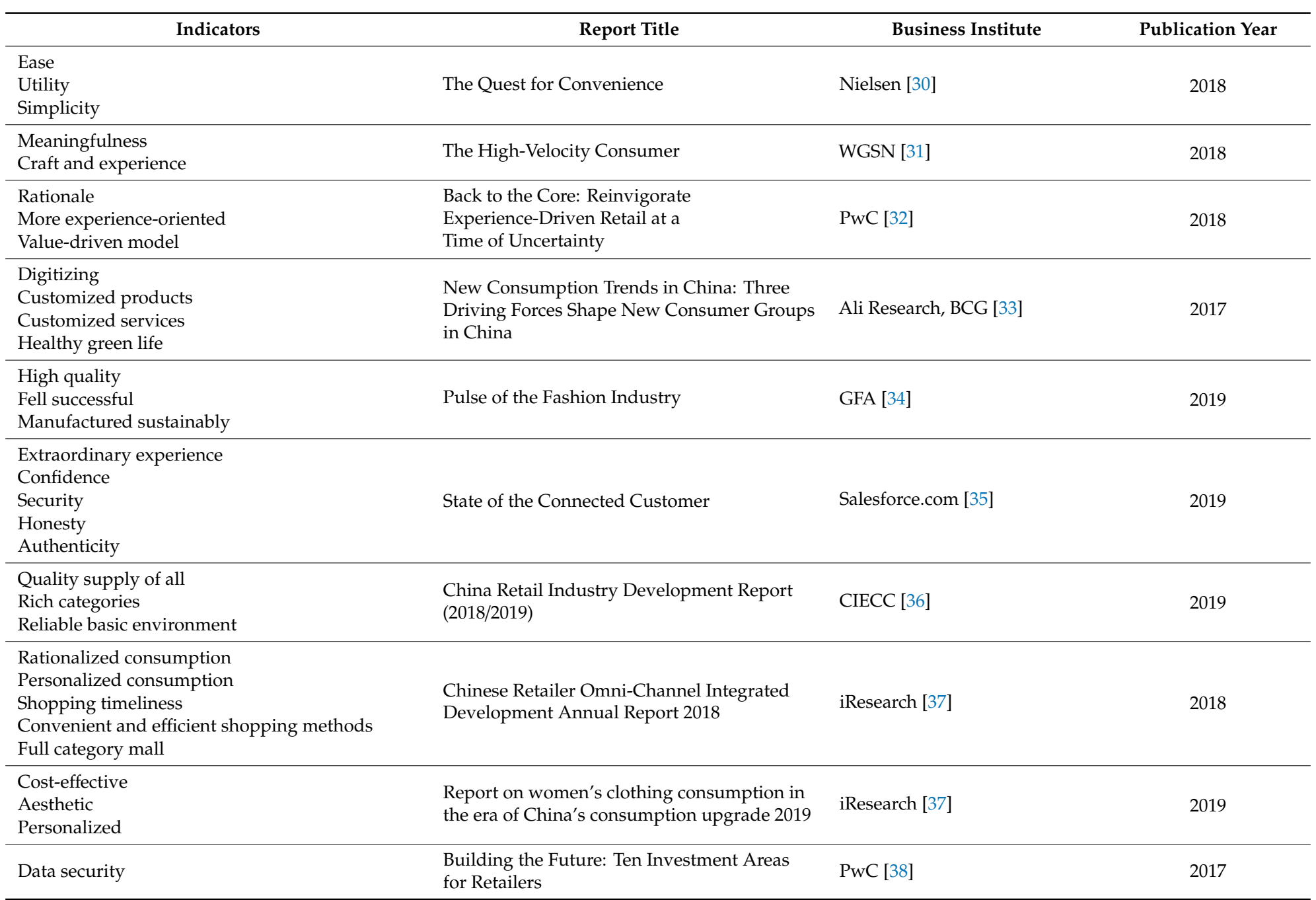

Abbreviations of company names are used throughout the table: BCG - Boston Consulting Group; GFA - Global Fashion Agenda; PwC - PricewaterhouseCoopers; CIECC - China International Electronic Commerce Center. 
Table 3. Management theory literature review: indicators and sources for the study variables.

\begin{tabular}{|c|c|c|}
\hline Indicators & Theoretical Source & Author \\
\hline $\begin{array}{l}\text { Perceived usefulness } \\
\text { Perceived ease of use }\end{array}$ & Technology Acceptance Model & Davis [39] \\
\hline $\begin{array}{l}\text { Expectation } \\
\text { Performance }\end{array}$ & Expectation Confirmation Theory & Oliver [40] \\
\hline $\begin{array}{l}\text { Impression } \\
\text { Perceived reality }\end{array}$ & Theory of Impression Management & Goffman [41] \\
\hline $\begin{array}{l}\text { Representation } \\
\text { Identity }\end{array}$ & Circle of Culture & Julier [42] \\
\hline $\begin{array}{l}\text { Reliability } \\
\text { Responsiveness } \\
\text { Assurance } \\
\text { Empathy }\end{array}$ & Total Quality Management & Parasuraman, Zeithaml, and Berry [43] \\
\hline $\begin{array}{l}\text { Aesthetic value } \\
\text { Social value } \\
\text { Authenticity value }\end{array}$ & Economics and Culture & Throsby [44] \\
\hline Unforgettable & Experience Economy & Gilmore and Pine [1] \\
\hline $\begin{array}{l}\text { Accessibility } \\
\text { Ease of use } \\
\text { Design } \\
\text { Responsiveness } \\
\text { Personalization }\end{array}$ & & Kaynama and Black [45] \\
\hline $\begin{array}{l}\text { Ease of use } \\
\text { Trust } \\
\text { Innovation } \\
\text { Communication }\end{array}$ & & Donthu and Yoo [46] \\
\hline $\begin{array}{l}\text { Reliability } \\
\text { Response } \\
\text { Risk } \\
\text { Experience }\end{array}$ & & Zeitham, Parasuraman, and Malhotra [47] \\
\hline
\end{tabular}


Table 4. Indicators and sources for the study variables.

\begin{tabular}{|c|c|c|}
\hline Variable & Variable Description & Source Literature \\
\hline Reliability & Ability to fulfill service commitments reliably and accurately & $\begin{array}{l}\text { Parasuraman, Zeithaml, and Berry [43] } \\
\text { Zeitham, Parasuraman, and Malhotra [47] }\end{array}$ \\
\hline Responsiveness & Quick response to or resolution of customer requirements & $\begin{array}{l}\text { Kaynama and Black [45] } \\
\text { Parasuraman, Zeithaml, and Berry [43] }\end{array}$ \\
\hline Caring & Caring and providing for customers with value-added services & $\begin{array}{l}\text { Zeitham, Parasuraman, and Malhotra [47] } \\
\text { Parasuraman, Zeithaml, and Berry [43] }\end{array}$ \\
\hline Perfect customer service & $\begin{array}{l}\text { Customer service representatives with professional knowledge and good } \\
\text { communication etiquette }\end{array}$ & $\begin{array}{l}\text { Donthu and Yoo [46] } \\
\text { Zeitham, Parasuraman, and Malhotra [47] } \\
\text { Salesforce research [35] } \\
\text { Boston consulting group [33] }\end{array}$ \\
\hline Usefulness & Provision of customized items to meet customization needs & $\begin{array}{l}\text { Nielsen [30] } \\
\text { Davis [39] }\end{array}$ \\
\hline Real-time & Real-time updates of logistics information and regular updates of styles & Variables obtained through expert interviews \\
\hline Innovative & Continuously optimized and updated platform & Donthu and Yoo [46] \\
\hline Contact Interactivity & Online and offline interaction & Variables obtained through expert interviews \\
\hline Efficiency & Efficient shipping & iResearch [37] \\
\hline Ease to use & Clear and easy-to-understand platform process orientation & $\begin{array}{l}\text { Nielsen [30], Kaynama and Black [45] } \\
\text { Donthu and Yoo [46] }\end{array}$ \\
\hline Safety of trade & Personal information security, payment security & $\begin{array}{l}\text { Salesforce research [35] } \\
\text { PwC [32] }\end{array}$ \\
\hline Practicality & Provision of personal image solutions & Variables obtained through expert interviews \\
\hline Simplicity & Simple and clear, not complicated & Nielsen [30] \\
\hline Intelligence & The value of smart body technology & Boston consulting group [33] \\
\hline Graphics & Clear graphic descriptions for fabrics and crafts & Variables obtained through expert interviews \\
\hline Healthiness & A more rational shopping mindset & Boston consulting group [33] \\
\hline Servitization & Exclusive, specific service processes & WGSN [31] \\
\hline
\end{tabular}


Table 4. Cont.

\begin{tabular}{|c|c|c|}
\hline Variable & Variable Description & Source Literature \\
\hline Social identity & Contribution to social identity & $\begin{array}{l}\text { Global Fashion Agenda [34] } \\
\text { Guy Julier [42] } \\
\text { David Throsby [44] }\end{array}$ \\
\hline Memorability & Special, impressive experience & $\begin{array}{l}\text { Pine and Gilmore [1] } \\
\text { WGSN [31] } \\
\text { PwC [32] } \\
\text { Salesforce research [35] } \\
\text { Zeitham, Parasuraman, and Malhotra [47] }\end{array}$ \\
\hline Uniqueness & Limited, unique and specially customized & Variables obtained through expert interviews \\
\hline Energy saving & Reduction of blind purchasing, and material and energy waste & $\begin{array}{l}\text { CIECC [36] } \\
\text { Global Fashion Agenda [34] }\end{array}$ \\
\hline Thriftiness & Reduction of unnecessary purchases & PwC [38], iResearch [37] \\
\hline Style design & Style design & Kaynama and Black [45] \\
\hline Professional appearance & Facilitation of a professional personal appearance & Global Fashion Agenda [34] \\
\hline Beautification & Enhancement of strengths and reduction of weaknesses & $\begin{array}{l}\text { iResearch [37] } \\
\text { David Throsby [44] }\end{array}$ \\
\hline Fit & Clothing size fit & iResearch [37] \\
\hline Tastefulness & Reflection of personal aesthetic taste and cultivation & Variables obtained through expert interviews \\
\hline Diversity of options & Provision of multi-category and multi-option customized items & $\begin{array}{l}\text { iResearch [37] } \\
\text { CIECC [36] }\end{array}$ \\
\hline Low cost & Low-cost, affordable customization & Variables obtained through expert interviews \\
\hline High quality & High-quality product & $\begin{array}{l}\text { Global Fashion Agenda [34] } \\
\text { CIECC [36] }\end{array}$ \\
\hline
\end{tabular}

Abbreviations of company names are used throughout the table: PwC - PricewaterhouseCoopers; CIECC - China International Electronic Commerce Center. Sources: Table developed by the authors based on analysis. 


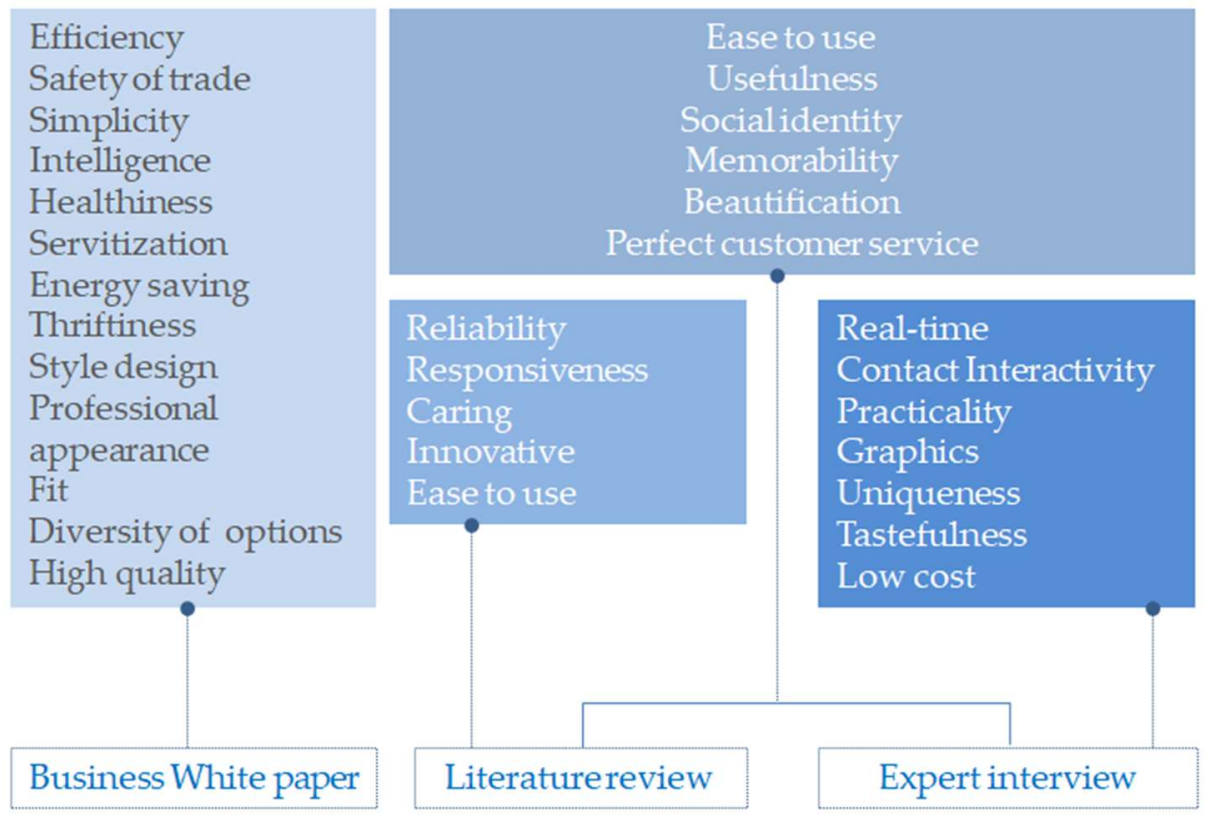

Figure 4. Phase I: Sources for indicators in the case study.

\subsection{Questionnaire Design and Statistical Analysis}

\subsubsection{Phase I Questionnaire Design}

The survey was conducted using an online questionnaire divided into four parts. The first part collected personal information from the interviewees. The purpose was to investigate whether differences in personal information would have different effects on clothing purchasing decisions. The question items included gender, age, and current occupation. In the second part, the questions were mainly concerned with the value elements about which the customers cared throughout the process of garment customization. The questions for each item were as follows: What channels do consumers use to get fashion news? What factors affect clothing purchase decisions? What are the needs of consumers for garment customization? and What is the value of the customer during the customization process? In the third part, the questions were mainly aimed at consumers' requirements for the use of Internet garment customization platforms. In the fourth part, the question was about garment customization as a clothing consumption behavior related to environmental sustainability. Each question corresponded to a variable and each variable was assigned multiple items. Likert scales, ranging from one to seven, were used to measure the answers to the questions and analyze the data based on the scores obtained from the answers.

\subsubsection{Collection of Information}

The survey population was set to individuals over 18 years of age with stable incomes and financial autonomy. Intentional sampling and snowball sampling were used to distribute the questionnaire until the number of samples reached more than five times the number of questions. The questionnaire was distributed to the Fujian, Shaanxi, Anhui, and Guangdong provinces of China from 4 September 2019 to 21 October 2019. A total of 237 questionnaires were distributed, of which 234 valid questionnaires were returned (132 from female participants and 102 from male participants). Gorsuch [48] argues that the ratio of sample size to the number of variables should be 5:1 or more. In fact, the ideal sample size should be 10 to 25 times the number of the variables, but this is difficult to achieve. Although a ratio of 5-10:1 is insufficient, good results can still generally be obtained [49,50]. For the respondents, the questionnaire items in this study were not easy to complete and they needed to have some knowledge or experience in customizing clothing. This also caused the recall of the questionnaire, which did not reach a ratio of 5:1. Therefore, to improve the reliability of statistical results, a commercial white paper issued by authoritative institutions was added as a source of variable extraction. 
The data showed that $55.12 \%$ of the survey participants came from the teaching industry, followed by $11.96 \%$ from the clothing industry, and $5.12 \%$ from administrative staff jobs (Table 5). Among the questionnaire respondents, $38.88 \%$ have experience with customization and $55.12 \%$ were willing to try it, indicating that Chinese consumers have a positive attitude towards custom-made clothing (Table 6).

Table 5. Participants' professional occupations.

\begin{tabular}{cccccccc}
\hline & Teacher & $\begin{array}{c}\text { Clothing } \\
\text { Industry Staff }\end{array}$ & $\begin{array}{c}\text { Management } \\
\text { Industry Staff }\end{array}$ & Seller & $\begin{array}{c}\text { Administration } \\
\text { Staff }\end{array}$ & Student & Others \\
\hline $\begin{array}{c}\text { Number } \\
\text { Proportion }\end{array}$ & 129 & 28 & 9 & 8 & 12 & 23 \\
\hline
\end{tabular}

Source: Table developed by the authors based on data analysis.

Table 6. Participants' intent to customize clothing on Internet platforms.

\begin{tabular}{ccc}
\hline Custom Intent & Subtotal & Proportion \\
\hline Have often used customization services & 2 & $0.85 \%$ \\
Have used customization services & 91 & $38.88 \%$ \\
Willing to try & 129 & $55.12 \%$ \\
Unwilling to try & 12 & $5.12 \%$ \\
\hline
\end{tabular}

Source: Table developed by the authors based on data analysis.

The results from the analysis represented in Table 6 show that, first, employees related to the clothing industry knew more about the situation in the industry regarding clothing customization, could clearly understand the topics set in the questionnaire, and gave highly reliable answers. Second, possibly due to the idea of professional identity, workers in the clothing industry had the highest frequency of consumption of customized shirts and team-made items. The consumers with higher degrees and/or an educational background (including teachers and administrative personnel), also had a higher probability of purchasing customizing clothing than did ordinary consumers. Therefore, the professional characteristics of respondents to the questionnaires in this study and the quality of their responses may offset the limited number of respondents and allow extrapolation to the wider population.

\subsubsection{Reliability and Validity of the Phase I Questionnaire}

Reliability tests were used to check the consistency of the questionnaire design and whether it met credibility standards. In this study, expert opinions were used as the research standard, and indicators of which experts did not reach a consensus were directly deleted. The criteria for deleting low-consensus indicators were based on Wang, $\mathrm{Wu}$, and $\mathrm{Wu}$ [51] and $\mathrm{Li}$ and Ho [52]. First, descriptive statistics were gathered using SPSS statistical software, with the mean (M) and standard deviation (SD) of each index obtained as the basis for evaluation. Where $M \geq 5.0$, the original appearance of the indicator was maintained, and where $4.5<\mathrm{M}<5.0$, the experts' opinions on the indicator were revised. Where $\mathrm{M} \leq 4.5$ and $\mathrm{SD} \geq 1$, the original indicator was deleted. Where $\mathrm{M}$ was too close to $4.5, \mathrm{SD} \geq 1$, and the attitude of experts leaned in favor of retaining the indicator, this indicator was also deleted to find indicators with a higher degree of consensus.

Using principal component analysis, taking eigenvalues of greater than 1 as the extraction factor standard, four factors were extracted in total. After the rotation, the eigenvalue of the first factor was 10.329, the eigenvalue of the second factor was 4.412, the eigenvalue of the third factor was 3.968, and the eigenvalue of the fourth factor was 2.794 . The explanatory variation was $34.431 \%, 14.706 \%$, $13.226 \%$, and $9.314 \%$, respectively, and a total of $71.676 \%$ of the variance was explained (Table 7 ).

There were common factors between the correlation matrices $(p<0.001)$. Factor analysis was suitable for this research question (Kaiser-Meyer-Olkin statistic $=0.957$ and significant Chi-square value of Bartlett's test of sphericity) (Table 8). 
Table 7. Principal component analysis of Phase I questionnaire.

\begin{tabular}{ccccccc}
\hline \multirow{2}{*}{ Component } & \multicolumn{3}{c}{ Initial Eigenvalues } & \multicolumn{2}{c}{ Rotation Sums of Squared Loadings } \\
\cline { 2 - 6 } & Total & $\begin{array}{c}\text { \% of } \\
\text { Variance }\end{array}$ & $\begin{array}{c}\text { Cumulative } \\
\text { \% }\end{array}$ & Total & $\begin{array}{c}\text { \% of } \\
\text { Variance }\end{array}$ & $\begin{array}{c}\text { Cumulative } \\
\text { \% }\end{array}$ \\
\hline 1 & 17.173 & 57.244 & 57.244 & 10.329 & 34.431 & 34.431 \\
2 & 1.640 & 5.467 & 62.712 & 4.412 & 14.706 & 49.137 \\
3 & 1.575 & 5.250 & 67.961 & 3.968 & 13.226 & 62.363 \\
4 & 1.115 & 3.715 & 71.676 & 2.794 & 9.314 & 71.676 \\
\hline
\end{tabular}

Extraction Method: Principal Component Analysis. Source: Table developed by the authors based on data analysis.

Table 8. KMO and Bartlett's test results.

\begin{tabular}{ccc}
\hline \multicolumn{2}{c}{ Kaiser-Meyer-Olkin Measure of Sampling Adequacy } & $\mathbf{0 . 9 5 7}$ \\
\hline & Approx. Chi-Square & 6858.113 \\
Bartlett's Test of Sphericity & $\mathrm{df}$ & 435 \\
& Sig. & 0.000 \\
\hline
\end{tabular}

Source: Table developed by the authors based on data analysis.

In this study, the remaining indicators were screened using the coefficient alpha. A general reliability test was conducted to assess how the Cronbach's $\alpha$ performed on the items under the same facet, and the coefficient was confirmed to be greater than 0.7. In addition, where the correlation was low or negative (the usual threshold is less than 0.3 ), the index could be improved by deleting the indicator, allowing for the reliability to be improved. Inappropriate indicators were deleted to obtain the high-consistency custom clothing value guidance of customers with strict standards. The remaining items were analyzed using principal component analysis and varimax rotation. Finally, four dimensions were obtained and the factors were named according to the reference index and sent for confirmation by the experts (Table 9). The reliability of the test questionnaire data met the threshold of 0.7 , suitable for factor analysis (Table 10). In the same dimensions, the factor loading was generally greater than 0.5 for each question and therefore had convergence validity.

Table 9. Rotated coefficient matrix a.

\begin{tabular}{|c|c|c|c|c|}
\hline & \multicolumn{4}{|c|}{ Components } \\
\hline & 1 & 2 & 3 & 4 \\
\hline Reliability & 0.828 & 0.213 & 0.230 & 0.146 \\
\hline Responsiveness & 0.803 & 0.257 & 0.276 & 0.202 \\
\hline Empathy & 0.787 & 0.257 & 0.260 & 0.201 \\
\hline Kind and courteous & 0.783 & 0.237 & 0.371 & 0.193 \\
\hline Usefulness & 0.781 & 0.218 & 0.265 & 0.129 \\
\hline Real-time online & 0.762 & 0.333 & 0.219 & 0.165 \\
\hline Innovative & 0.746 & 0.254 & 0.319 & 0.224 \\
\hline Interactivity & 0.746 & 0.334 & 0.188 & 0.160 \\
\hline Efficient & 0.719 & 0.298 & 0.100 & 0.282 \\
\hline Ease to use & 0.718 & 0.246 & 0.316 & 0.036 \\
\hline Safety of data & 0.712 & 0.123 & 0.443 & 0.008 \\
\hline Practical & 0.706 & 0.360 & 0.291 & 0.140 \\
\hline Simple & 0.698 & 0.136 & 0.284 & 0.162 \\
\hline Intelligent & 0.676 & 0.276 & 0.142 & 0.232 \\
\hline Detailed description & 0.674 & 0.347 & 0.256 & 0.154 \\
\hline Healthy lifestyle & 0.552 & 0.544 & 0.144 & 0.374 \\
\hline Servitization & 0.177 & 0.738 & 0.199 & 0.028 \\
\hline Social identity & 0.311 & 0.711 & 0.136 & 0.213 \\
\hline Unforgettable & 0.352 & 0.703 & 0.101 & 0.224 \\
\hline Uniqueness & 0.321 & 0.567 & 0.447 & 0.007 \\
\hline
\end{tabular}


Table 9. Cont.

\begin{tabular}{lcccc}
\hline & \multicolumn{4}{c}{ Components } \\
\cline { 2 - 4 } & $\mathbf{1}$ & $\mathbf{2}$ & $\mathbf{3}$ & $\mathbf{4}$ \\
\hline Energy saving & 0.519 & 0.554 & 0.114 & 0.373 \\
Thrifty & 0.512 & 0.515 & 0.029 & 0.438 \\
Fashion design & 0.281 & -0.022 & 0.753 & 0.376 \\
Customized personal style & 0.358 & 0.362 & 0.682 & 0.058 \\
Beautify & 0.401 & 0.359 & 0.639 & 0.172 \\
Fitted & 0.456 & 0.245 & 0.621 & 0.258 \\
Tasteful & 0.365 & 0.434 & 0.580 & 0.232 \\
Diverse options & 0.180 & 0.195 & 0.140 & 0.738 \\
Low cost & 0.126 & 0.224 & 0.198 & 0.737 \\
High quality & 0.279 & -0.056 & 0.546 & 0.618 \\
\hline
\end{tabular}

Extraction Method: Principal Component Analysis. Rotation Method: Varimax with Kaiser Normalization. a. Rotation converged in 12 iterations Source: Table developed by the authors based on data analysis.

Table 10. Components' score extraction.

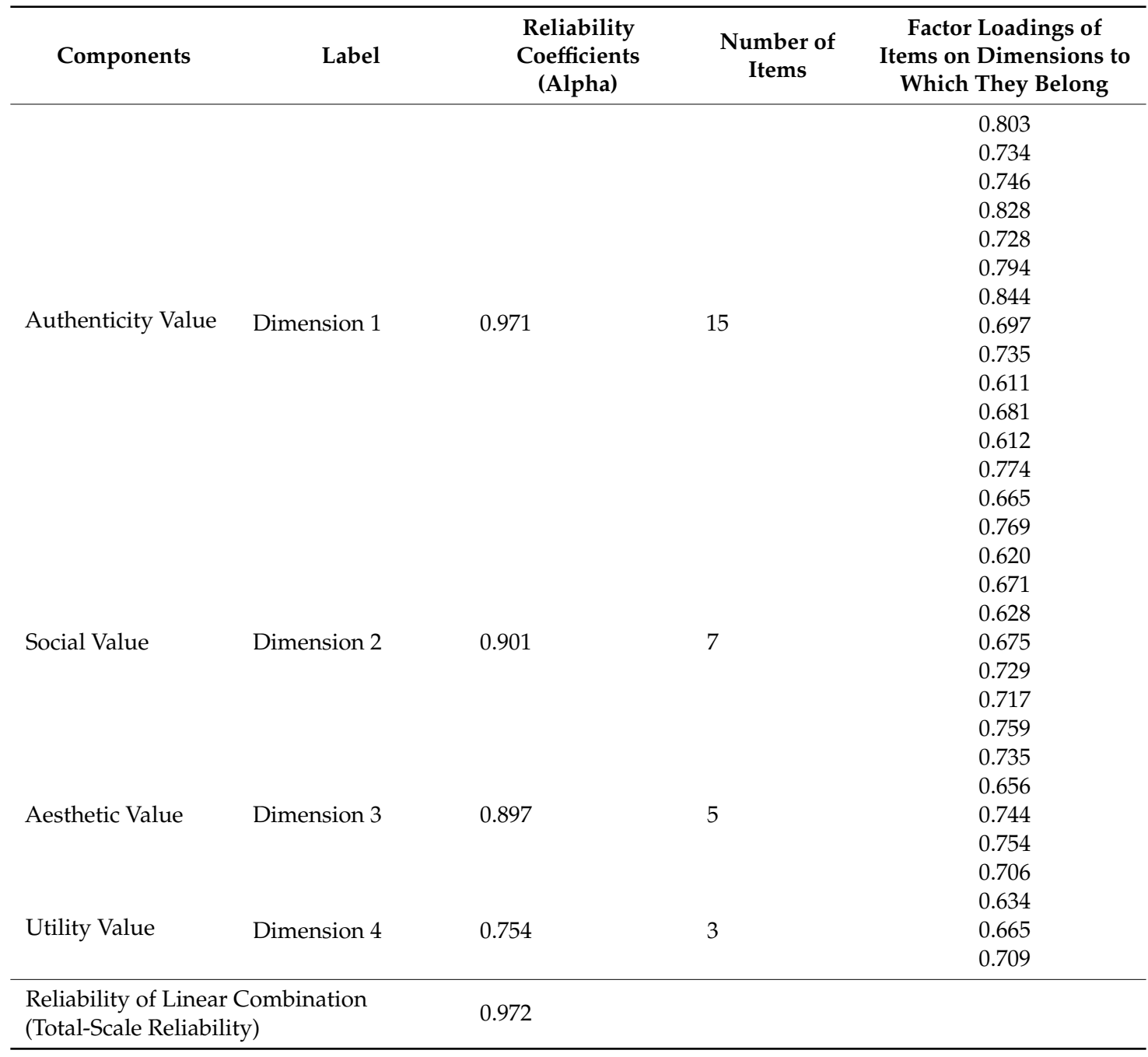

The percentage of variance extracted by the four factors was 71.42\%; Extraction Method: Principal Component Analysis; Rotation Method: Varimax with Kaiser Normalization; a. Rotation converged in 7 iterations. Sources: Table developed by the authors based on data analysis.

The rotated coefficient matrix reflected the correlation between the principal component and the original variable. From Table 9, it is evident that principal component 1 aligned with reliability, 
responsiveness, empathy, kind and courteous, usefulness, real-time online, innovative, interactivity, efficient, easy to use, safety of data, practical, simple, intelligent, detailed description, and healthy lifestyle factors. The correlation between principal component 2 and the factors servitization, social identity, unforgettable, uniqueness, energy-saving, and thrifty was strong, and the correlation between principal component 3 and the factors fashion design, customized personal style, beautify, fitted, and tasteful were stronger. The correlation between principal component 4 and the diverse options, low cost, and high-quality factors was also strong. The purpose of using the rotation was to make the factors clearer, to provide sufficient information. Using principal component analysis for factor extraction, the rotation method uses varimax with Kaiser Normalization. The data were transformed to fit the assumptions of the statistical model. The purpose of the factor rotation axis was to cover the largest range in space through the rotation of the coordinate axis to achieve the largest amount of variation interpretation.

By rotating the axis, the tendency of each factor (axis) to be uncorrelated with the variable could be strengthened so that several questions that were already very relevant remained high-loading, which was conducive to the naming and interpretation of the factors. The criterion of factor load was 0.71 for excellent, 0.63 for very good, 0.55 for good, and the one with the largest loading score was given priority. The factor loading score of the authenticity value component was 0.971 ; the factor loading score for the social value component was 0.901 ; the factor loading score for the aesthetic value component was 0.897 , and the factor loading score for the utility value component was 0.754 . Table 10 shows that the loading scores of the four factors were all excellent and suitable for factor naming.

\subsection{Analysis and Verification}

The construction of the evaluation index through expert interviews and questionnaire analyses was the first goal. The values were named authenticity value, social value, aesthetic value, and utility value. The second level (the objective level) was the construction of the evaluation detail index that constitutes the first level dimension (Figure 5).

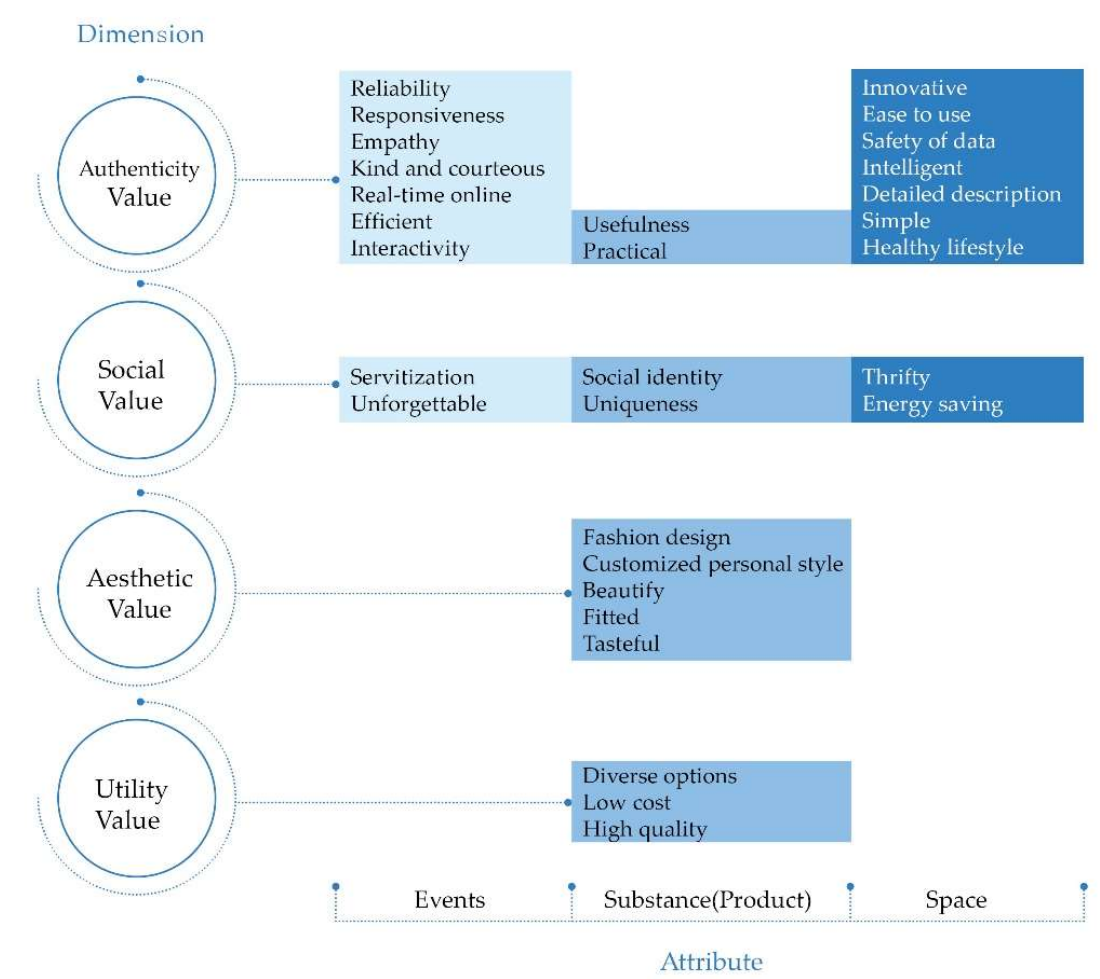

Figure 5. Customer value dimensions by component and customer value indicators by attribute. Source: Figure developed by the authors based on analysis. 


\subsubsection{Dimension 1: Authenticity Value}

The first dimension was called authenticity value. Throsby [44] stated that authenticity value "refers to the fact that the work is the real, original, and unique artwork which it is represented to be." Digital clothing customization first needs to meet consumers' basic functional requirements: usefulness and practicality. The customized service delivery methods also have become more diversified. The requirements for online customer service have changed significantly, which have become more detailed, including reliability, responsiveness, empathy, kind and courteous tone, real-time online presence, and efficiency. The value of digital clothing customization is generated during the online interaction between consumers and customer service. The customization platform requires using digital technology in the content of clothing customization. Content refers to the detailed information that clothing as a product needs to be displayed on a digital platform; the display of product content is assisted and empowered by digital solutions, including user connectivity, applets, clouds, and AIs. Content requires many perspectives and dimensions to be able to connect the product's functions. This includes the product dimensions of innovative, easy to use, safety of data, intelligent, detailed description, simple, interactive, and healthy lifestyle.

From the perspective of supply, the support of digital technology has completely changed the customer value of clothing in terms of ordering, logistics, and after-sales services. Providing personalized rewards, products, and services, companies design customized goods and services for customers, helps to build sustainable relationships. At the same time, digital technology can streamline and accelerate the supply process to reduce costs and processing time.

\subsubsection{Dimension 2: Social Value}

The second dimension is social value. The same method (service, product, and platform) was used to combine the variables. In the social value dimension, the service, product, and platform perspectives for variable composition were still used because digital clothing customization is a new retail method. Under social sustainable development awareness, Chinese consumers are more concerned with the experience of being served, the symbolism of the products, and the brands' sense of social responsibility.

Other research shows that superior customer service is at the core of online retail success. Many online customers have a low sense of loyalty to existing websites or online brands. With this in mind, it is necessary to incorporate service quality into the product portfolio provided to customers, to increase their overall value perception. From the perspective of product attributes of social value, clothing as a social symbol conveys the feeling of being connected with others and expresses itself through exclusive personal characteristics and stylization. American sociologist Thorstein Veblen [53] proposed the term "conspicuous consumption" in his book The Theory of the Leisure Class. Clothing is a manifestation of money culture. In the display class, clothing is better than other consumption methods. The social characteristics of clothing customization are reflected in the fact that it is directed towards rational consumption and a design solution based on consumer self-image. It seeks differentiated garment products and sustainable garment consumption, behaviors, and lifestyles.

\subsubsection{Dimension 3: Aesthetic Value}

The third dimension identified in this study was aesthetic value. From the perspective of aesthetic functionality, aesthetic value represented the indicators fashion design, customized personal style, beautify, fitted, and tasteful. These can be interpreted as basic requirements for consumer fit, modification (constituted by attractive images and customized dressing schemes), reproducing the consumer's personal aesthetic tastes, and re-constructing and identifying the brand to achieve customer loyalty. The customized product will eventually be internalized into the individual's aesthetic tastes and habits, serving to influence their next purchase. From the perspective of sustainable fashion, custom clothing not only meets the basic functional needs of beauty, but also prompts consumers to redefine the relationship between beauty and customization. What people need is clothing that is 
fashionable, while fulfilling certain social characteristics and other functions. This need is in line with the aesthetic and mainstream cultural trends of consumers. Sturken and Cartwright [54] proposed that self-identity was constructed in a larger field than that of the family. The transformation of commodities and the interpretation of commodity meanings would occur through the processes of reproduction, identification, production, consumption, and regulation, and each process was connected through many interactions and other processes [42]. Some scholars have argued that in a consumer society, people based their status and self-image, at least partially, on their purchases and uses of goods. Consumers defined themselves through consumerist views by purchasing. Commodities conveyed symbols through content, including wealth, status, aesthetics, morality, personality traits, and value orientation. Brands provided more choices of aesthetic symbols to meet the personalized consumption needs of aesthetic symbols. Therefore, aesthetic value could trigger and continuously promote customer perceived value and brand loyalty.

\subsubsection{Dimension 4: Utility Value}

The fourth dimension of customer value was utility value, which included the indicators diverse options, low cost, and high quality. The theory of utility in Western economics holds that value is based on utility, and that utility is completely subordinate to consumers' needs, likes and dislikes, as well as to fashion. Customized garments are first consumed as an attribute of a product, so the utility of a product is also used as an evaluation criterion. The value of the garment changes with individuals' needs, their psychological perceptions, and the manufacturers' production methods. In the field of consumption, the consumer's lack of desire and pursuit of satisfaction constitutes the consumer's desire for consumption and the realization of consumer desire is utility.

The Internet's contribution to business innovation lies in the transformation of the digital field to incorporate the relationship between people and goods. Consumption upgrades are based on the continuous development of social and economic levels so that consumers can enjoy benefits and be able to provide an adequate supply of rational value while allowing consumers to experience greater value gain. Hisashi [55] argued that companies needed to consider: (1) the need to make products that customers wanted; (2) the need to enhance the investigation of customer preferences and market segments; and (3) the need to either pay attention to the advancement of raw materials or the differentiation of sales. From the perspective of the sustainable development of the clothing industry, clothing customization services solve the industry inventory problem through on-demand manufacturing. From the perspective of the individual needs of consumers, consumers' participation in production and the realization of differentiated design solutions are supplementary to conventional clothing consumption and sustainable fashion consumption.

\section{Phase II: Evaluation of Customer Value Indicators in Clothing Digital Customization Experiences}

Through the factor analysis of Phase I, we obtained the customer value variables (demand side) of the custom apparel consumer. In Phase II, we used Phase I indicators to score performance for customized platforms. The end goal of the analysis was to understand the new consumer experience of digital customization and customer evaluation (Figure 6).

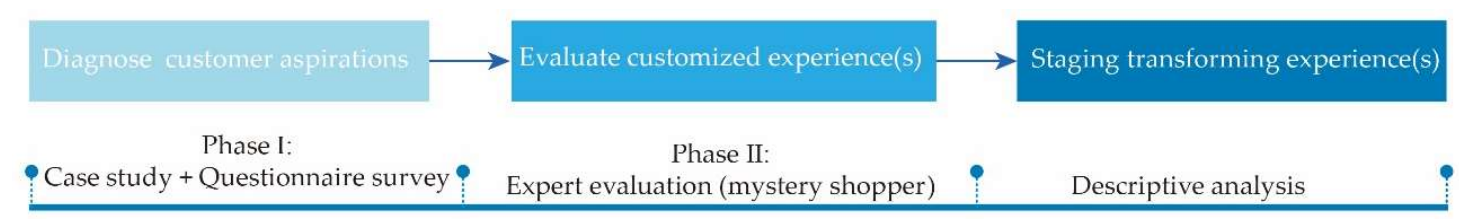

Figure 6. Research phases and analytical methods. Source: Figure adapted and adjusted from Pine and Korn, 2011 [1]. 


\subsection{Assessment Method}

The expert group evaluated customer value provided by clothing digital customization platforms. Four male and two female experts participated in this study. Scores were given on Likert scales ranging from 1 to 7 , with higher scores indicating that the customization platform provided a higher degree of customer value. Before the evaluation, the experts needed to fully understand the brand positioning and product characteristics of the target. They could then perform an experience evaluation for the digital customization services. The evaluation sample was selected from the men's digital customization platforms. Men's suits were chosen as the focus because the men's fashion market is an emerging high-value market segment. In Figure 7, platform 1 (MatchU), which provides men's clothing customization, offers custom shirts starting at 199 RMB; platform 2 (iOrder), which provides a broad range of categories for men's apparel customization, offers custom shirts starting at 399 RMB; and platform 3 (YBren), which provides a wide range of categories for men's and women's clothing customization, offers custom shirts starting at $348 \mathrm{RMB}$. The custom-made price of a shirt is around $200 \mathrm{RMB}$, which is based on the concept of a small change account. When the funds in the change account are consumed, people have fewer psychological concerns. In China, most consumers perceive $200 \mathrm{RMB}$ as within the range of small change. When the amount is more than $200 \mathrm{RMB}$, people will be more cautious about their spending (the maximum amount of WeChat package is also $200 \mathrm{RMB}$ ). Figure 8 shows the shirt module customization options provided by one of the customized platforms and the mandatory items for describing the physical characteristics of customers.

\subsection{Expert Verification Data Analysis}

The results of the questionnaire used descriptive statistical analysis. The data differences between the three customized platforms were reflected in the dimensions of social value and aesthetic value (Figure 9). The energy-saving value and thrifty value in the social value dimension referred to the social care and green production responsibilities that the manufacturing company must bear in the process of sustainable and digital transformation and development of awareness. This also reflects the fact that Chinese consumers have shown unprecedented expectations for rational consumption and sustainable fashion when customizing their clothing.

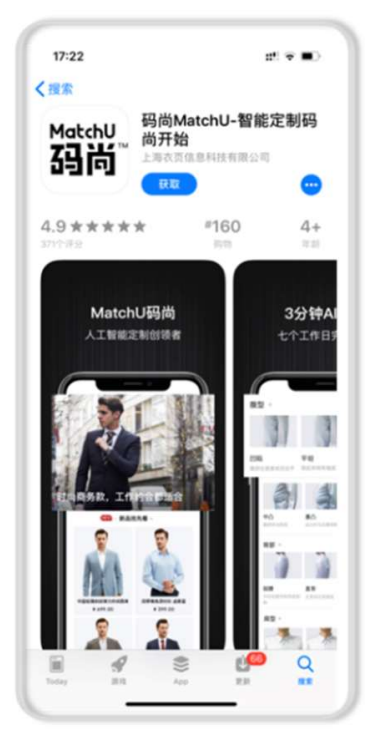

(a)

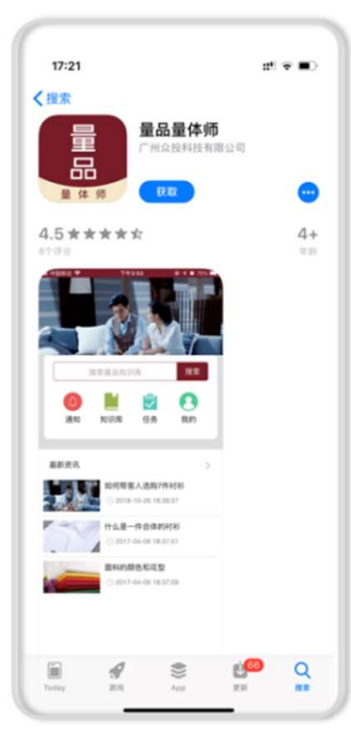

(b)

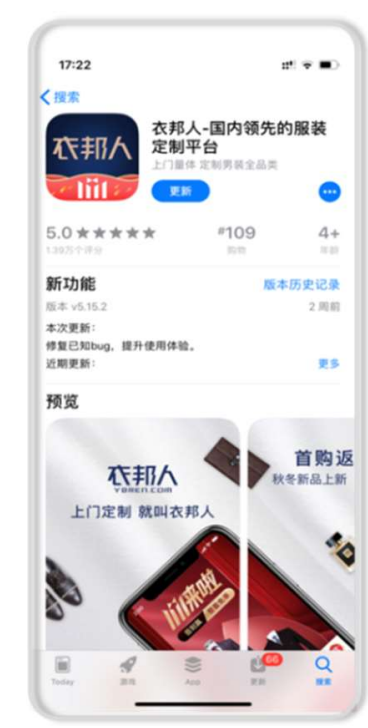

(c)

Figure 7. Clothing customization app. Source: (a) collected from MatchU apple app screenshot; (b) collected from iOrder apple app screenshot; (c) collected from YBren apple app screenshot. 


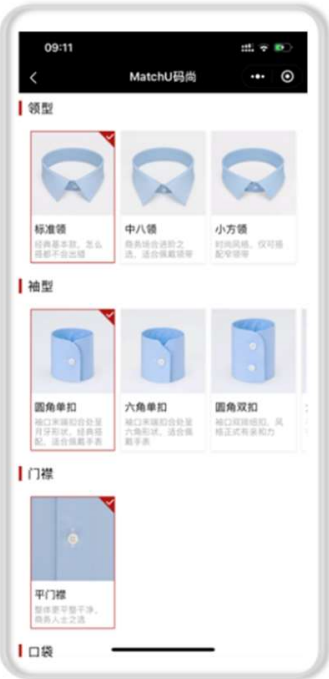

(a)

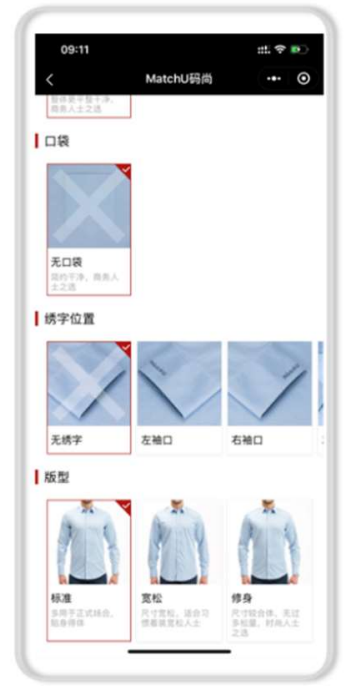

(b)

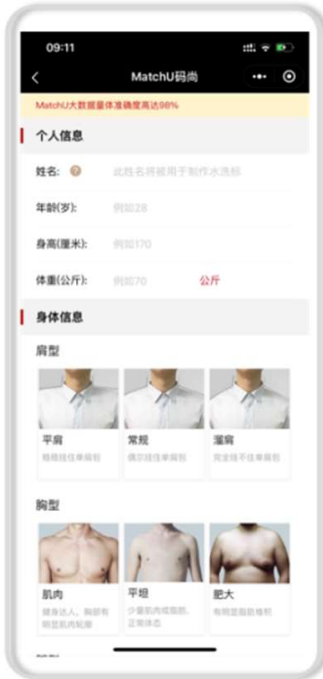

(c)

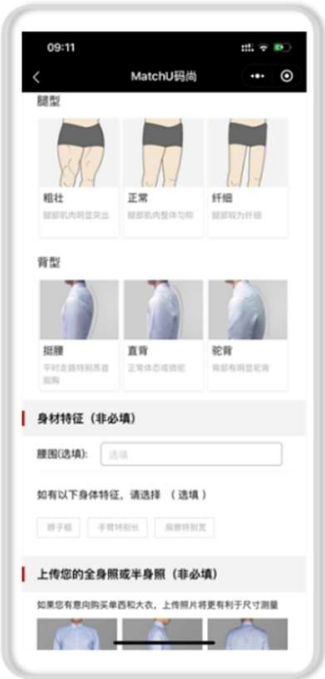

(d)

Figure 8. Module in clothing digital customization app. Source: Figure (a-d) collected from MatchU apple app screenshot.

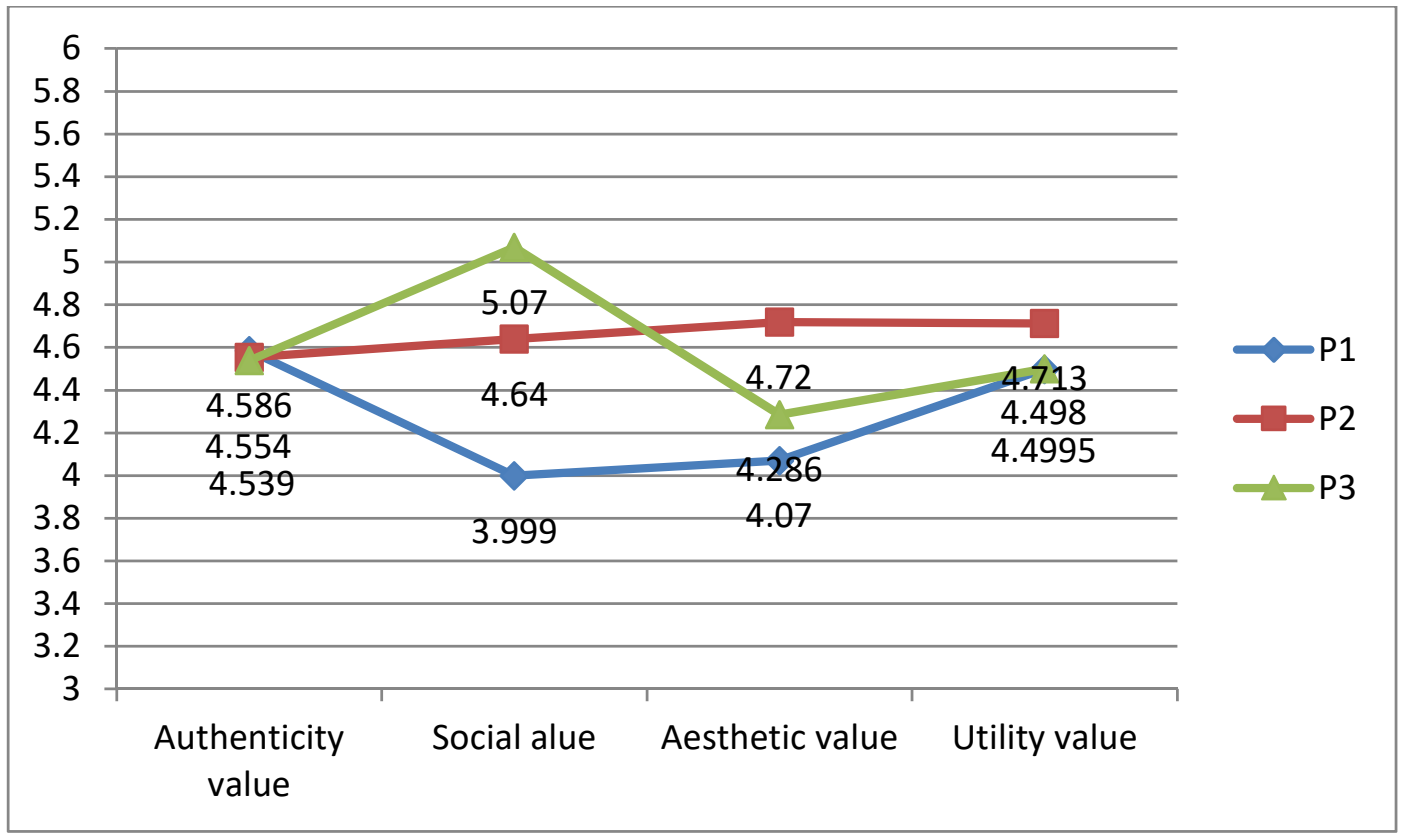

Figure 9. Evaluation scores for custom clothing platforms. Source: Figure developed by the authors based on analysis.

The three participating platforms selected in this study all belonged to the made-to-measure customization of the ready-to-wear category. In the production process, all relied on the flexible manufacturing of industrial production lines. The production of the assembly line required a modular process, which means that customers could not fully customize their orders. The shopping experience of consumers was thus merely a combination of modules and self-service online shopping. Customized clothing was widely advertised, but the actual experience was considerably different from the traditional definition of customized clothing.

Although the three clothing customization platforms selected for this research provided consumers with only modular customized experiences at the level of digital technology, its essence is the combination of products. The digital clothing customization model, as an emerging production and marketing 
model, can still meet the customization needs of specific consumer groups. In the new retail e-commerce era proposed by Alibaba, digital technology is developing the customer experience (content, products, and services) in the consumer field with unprecedented momentum and a new type of supply, oriented by digital technology, has been constructed.

\section{Results and Discussion}

\subsection{Results Summary}

Phase I was focused on consumers and explored indicators of customer value. We established four customer value dimensions: authenticity value, social value, aesthetic value, and utility value. The authenticity value was composed of 16 indicators that are significant to the data scores. This result was consistent with the opinion put forward by Gilmore and Pine [56]. In China, consumers of custom-made clothing have an appetite for products that has surpassed the basic requirements of product function, service, and quality, and they now pursue authenticity.

Table 11 shows the difference between the two phases of the research results, following the conversion of the Phase II data. The results of Phase II show that consumers' evaluation of digital customization is either high or low. Among them, the scores of authenticity value and aesthetic value dimension show that the products do not meet the consumers' expectations. The score performance in the social value and utility value dimensions shows that the products exceeded the consumers' expectations (Figure 10). If we define the dimensions with high scores as the new customer value, then we can also see that they are associated with new customer sacrifice (the low-scoring dimensions).

Table 11. Score results of the customer value dimensions obtained in Phases I and II.

\begin{tabular}{clcccc}
\hline & & $\begin{array}{c}\text { Authenticity } \\
\text { Value }\end{array}$ & $\begin{array}{c}\text { Social } \\
\text { Value }\end{array}$ & $\begin{array}{c}\text { Aesthetic } \\
\text { Value }\end{array}$ & $\begin{array}{c}\text { Utility } \\
\text { Value }\end{array}$ \\
\hline \multirow{2}{*}{ Phase I } & Initial value & 0.971 & 0.901 & 0.897 & 0.754 \\
\hline \multirow{2}{*}{ Phase II } & Initial value & 4.559 & 4.569 & 4.358 & 4.57 \\
& Converted value & 0.9118 & 0.9138 & 0.8716 & 0.914 \\
\hline
\end{tabular}

Initial value sources from: Phase I - Component Score (Table 10); Phase II - Average score (Figure 9) Converted value: $5 /$ (initial value) $=1 /($ converted value) Source: Table developed by the authors based on analysis.

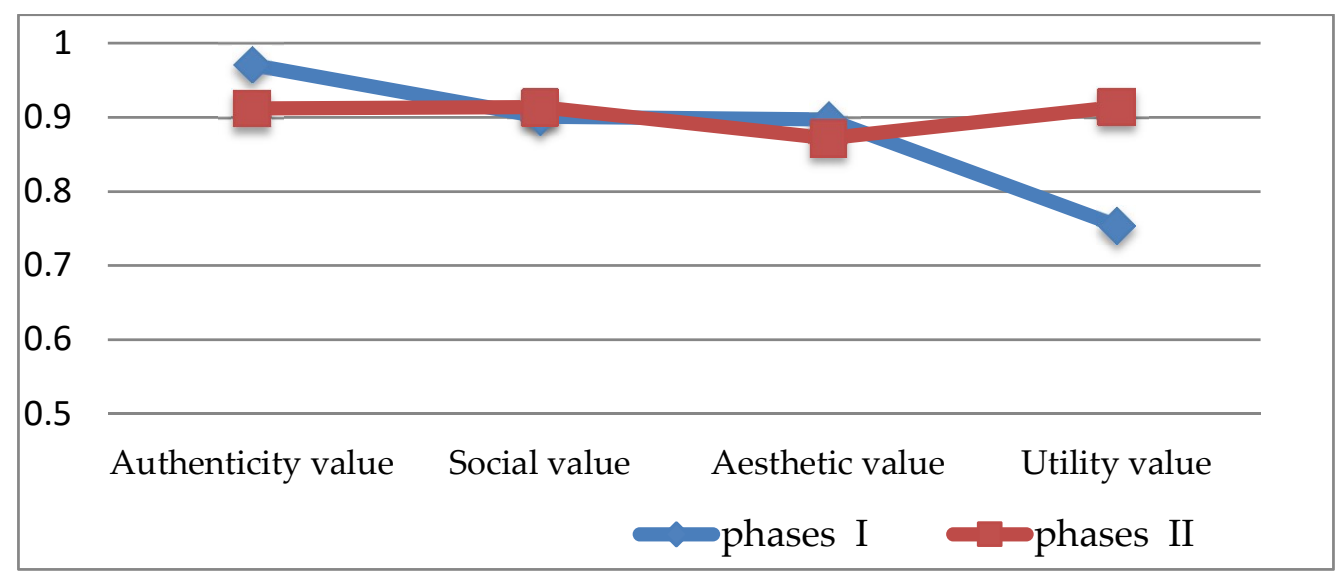

Figure 10. Comparison of customer value dimension scores obtained in phases I and II. Source: Figure developed by the authors based on analysis.

The approaches to customization (types of sacrifice) proposed by Gilmore and Pine in The Experience Economy [1] is an appropriate framework for the results of our study (Figure 11). 


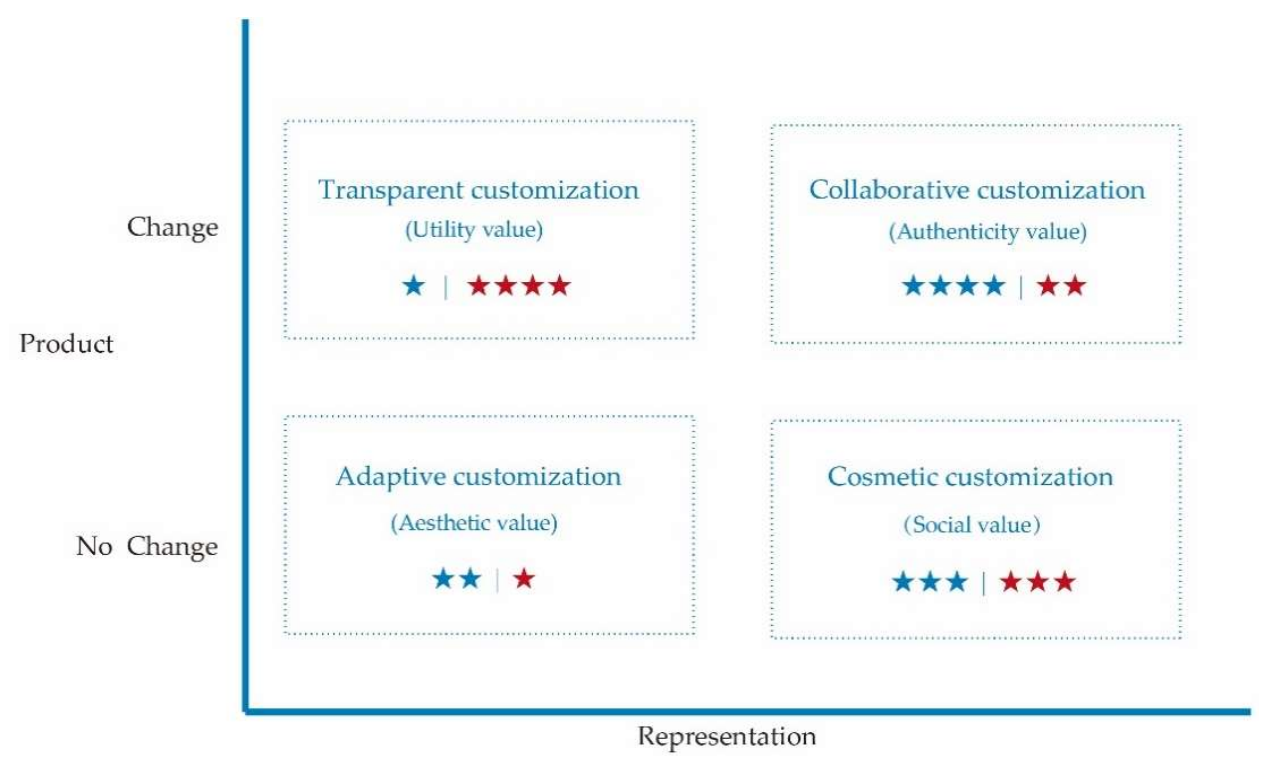

Figure 11. Approaches to clothing digital customization (types of customer sacrifice). Source: Figure adapted and adjusted from Gilmore and Pine, 2011 [1].

- Transparent customization corresponds to the utility value, which is a discovery that simplifies the interaction process between the buyer and the seller. The customer discovers the differences inherent in the product through a simple product appearance. Customized production of clothing solves the consumers' needs for the suitability and comfort of clothing, which is of practical value.

- Collaboration customization corresponds to the authenticity value, which is an exploratory experience. This experience emphasizes the interaction between the customizer and the customer, and the final realized value is determined by both parties. From their participation in the design through to the finalization of customized products, customers focus on their personal needs and thus reduce the trade-offs that must normally be made for mass-produced products.

- Adaptive customization corresponds to aesthetic value, which belongs to an experimental experience- the product itself. Its expression does not change for each customer as the system provides embedded customizable functions. The goal of such customized design systems is to digitize consumer behavior. The system will automatically identify and recommend solutions for personal images based on the user's previous operating behavior, thereby simplifying the user's selection process.

- Cosmetic customization corresponds to social value, which refers to a satisfying experience. For a customized product, losses to the customer are not in terms of the product itself, but of its manifestation-how the product is packaged and presented, and when and where and how it is delivered. Customizers need to customize the packaging of products, such as custom printing or packaging methods, marketing materials, delivery methods, exclusive labels, and other personalized expressions to provide each customer with a "specific to me" experience. By customizing the representation of a standardized offering, the customizer gives its customers personalized attention [1]. Desjeux [57] believes that consumption has a social belonging effect in the sociological sense and a lifestyle effect in the market sense.

\subsection{Discussion}

Different customization methods are used to solve different customer sacrifices, thereby forming a unique consumer experience. Customer expectations are dynamic, and the collection of customer expectations and product performance can be used to formulate improved action plans [1]. We use the concept of Chinese retail business (person/service, product, space) to classify customer value indicators by attributes so that the indicators provide more guidance for precision marketing. Our terms social 
value and aesthetic value are derived from the literature [1,7,44]. In contrast to previous studies [8-11], utility value and authenticity value in the results of our study are based on the product value, and an authentic clothing product experience [29].

From the perspective of production, the digital customized production of clothing is still industrialized mass customization, and there is still much room for improvement in its digital marketing experience. The clothing customization experience in the digital economy is inseparable from both the product manager's thinking (utility, aesthetics) and craftsmanship thinking (authentic products, humanized services, and unforgettable experience). In the era of the digital economy, consumers are eager for a true digital transformation [58].

\section{Conclusions}

From the perspective of the sustainable development of consumption and production, the digital transformation of the clothing customization industry is no longer an optional solution, but instead an essential trend. It is predicted that digital technology will become increasingly mature in commercial marketing, and such dynamic markets require innovative user research. As of May 2020, the most popular marketing model in the Chinese retail market is e-commerce live streaming. New retail space and time are created, new customer experiences are stimulated, customer value will be redefined, and new customers' sacrifices will decrease.

This study used hybrid research methods to conduct an empirical investigation of customer value and performance evaluation, using the "people, products, place" methodology of China's retail business to classify customer value indicators.

A limitation of this study is that the questionnaire (for more details see Appendix A Table A1) is restricted to the clothing industry, as an exploratory survey and descriptive analysis. The descriptive research method has the advantage that a market can be segmented and described, resulting in a more structurally manageable method [57]. Future research will require the addition of diagnostic analysis, predictive analysis, and prescription analysis.

Under the new retail format in China, direct factory supply and consumer reverse customization production provide a vision for the development of a green industry on both the apparel supply side and the consumer side. Meeting needs and creating experiences correspond to the product manager's thinking and craftsmanship thinking, respectively. Both of these perspectives are prevalent in both the Internet industry and traditional industries embracing Internet-based technology. The clothing manufacturing industry, while providing digital customized production, needs to determine more than just how to sell goods with different patterns. It also needs to use craftsmanship thinking to carefully craft products in pursuit of the ultimate goal of providing ordinary users with real product experience and aesthetic appeal.

In the era of the digital economy, establishing, tracking, observing, and re-examining the authenticity and effectiveness of customer insights requires multimethod investigations. The industrial scene is complex and diverse, and companies cannot accomplish market research on customer value overnight. This study presents an initial framework to build upon. The infusion of digital technology into the technical thinking of the apparel customization industry is like a stone thrown into a pool: The ripples it forms spread gradually.

Author Contributions: W.-J.Y. developed the research design, collected the data, and conducted the analysis. W.-J.Y. and S.-C.C. wrote the manuscript. All authors have read and agreed to the published version of the manuscript.

Funding: This research was supported by the Project of Central Leading Local Science and Technology Development (Grant No.2018L3012), China. This research also supported by the Open Project Program of Fujian Garment Creative Design Center (Grant No. MJ2019B005), China.

Conflicts of Interest: The authors declare no conflict of interest. 


\section{Appendix A}

Table A1. Questionnaire on Sustainable Customer Value in Digital Clothing Customization.

\begin{tabular}{|c|c|c|}
\hline & \multicolumn{2}{|c|}{ Questionnaire on Sustainable Customer Value in Digital Clothing Customization } \\
\hline NO & \multicolumn{2}{|c|}{ Main Question } \\
\hline 1. & \multicolumn{2}{|c|}{ Your gender? } \\
\hline 2. & \multicolumn{2}{|c|}{ Your age? } \\
\hline 3. & \multicolumn{2}{|c|}{ Your current occupation? } \\
\hline \multirow[t]{2}{*}{4.} & \multicolumn{2}{|c|}{ Have you ever customized clothing? } \\
\hline & What are the chann & nion information? \\
\hline \multirow{3}{*}{5.} & $\square$ WeChat $\square$ Weibo $\square$ Instagrar & vspapers $\square$ official websites \\
\hline & $\square$ fashion shows $\square$ e-commerce $\square$ & $\square$ purchasing $\square$ asking friends \\
\hline & $\square$ Word of mouth $\square$ web recomme & $s$ Facebook $\square$ Twitter $\square$ others \\
\hline \multirow{11}{*}{6.} & The following options may affect & our clothing purchase decision? \\
\hline & \multicolumn{2}{|c|}{$\begin{array}{l}\text { ngly important, (2) moderately important, (3) slightly important, (4) neutral, } \\
\text { (5) slightly important, (6) moderately important, (7) very important }\end{array}$} \\
\hline & - Style design & $\square 1 \square 2 \square 3 \square 4 \square 5 \square 6 \square 7$ \\
\hline & - product quality & $\square 1 \square 2 \square 3 \square 4 \square 5 \square 6 \square 7$ \\
\hline & - Complete category & $\square 1 \square 2 \square 3 \square 4 \square 5 \square 6 \square 7$ \\
\hline & Discount & $\square 1 \square 2 \square 3 \square 4 \square 5 \square 6 \square 7$ \\
\hline & - Service quality & $\square 1 \square 2 \square 3 \square 4 \square 5 \square 6 \square 7$ \\
\hline & - Celebrity endorsements & $\square 1 \square 2 \square 3 \square 4 \square 5 \square 6 \square 7$ \\
\hline & - Brand Culture & $\square 1 \square 2 \square 3 \square 4 \square 5 \square 6 \square 7$ \\
\hline & - Brand awareness & $\square 1 \square 2 \square 3 \square 4 \square 5 \square 6 \square 7$ \\
\hline & - Social responsibility & $\square 1 \square 2 \square 3 \square 4 \square 5 \square 6 \square 7$ \\
\hline \multirow{15}{*}{7.} & \multicolumn{2}{|c|}{ Clothing customization is to meet what your requirements? } \\
\hline & \multicolumn{2}{|c|}{$\begin{array}{l}\text { (1) Strongly disagree, (2) moderately disagree, (3) slightly disagree, (4) neutral, } \\
\text { (5) slightly agree, (6) moderately agree, (7) strongly agree }\end{array}$} \\
\hline & - Functional & $\square 1 \square 2 \square 3 \square 4 \square 5 \square 6 \square 7$ \\
\hline & - Professional & $\square 1 \square 2 \square 3 \square 4 \square 5 \square 6 \square 7$ \\
\hline & - popular & $\square 1 \square 2 \square 3 \square 4 \square 5 \square 6 \square 7$ \\
\hline & - Sense of ceremony & $\square 1 \square 2 \square 3 \square 4 \square 5 \square 6 \square 7$ \\
\hline & - Satisfaction & $\square 1 \square 2 \square 3 \square 4 \square 5 \square 6 \square 7$ \\
\hline & - Fit & 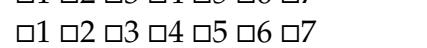 \\
\hline & - Body & $\square 1 \square 2 \square 3 \square 4 \square 5 \square 6 \square 7$ \\
\hline & - Decent & $\square 1 \square 2 \square 3 \square 4 \square 5 \square 6 \square 7$ \\
\hline & - Tasteful & $\square 1 \square 2 \square 3 \square 4 \square 5 \square 6 \square 7$ \\
\hline & - Comfortable & $\square 1 \square 2 \square 3 \square 4 \square 5 \square 6 \square 7$ \\
\hline & - Stylish & 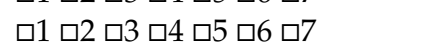 \\
\hline & - Individuality & $\square 1 \square 2 \square 3 \square 4 \square 5 \square 6 \square 7$ \\
\hline & - High quality & $\square 1 \square 2 \square 3 \square 4 \square 5 \square 6 \square 7$ \\
\hline \multirow{14}{*}{8.} & \multirow{2}{*}{\multicolumn{2}{|c|}{$\begin{array}{l}\text { What value do you focus on in the clothing customization process? } \\
\text { (1) Strongly disagree, (2) moderately disagree, (3) slightly disagree, (4) neutral, } \\
\text { (5) slightly agree, (6) moderately agree, (7) strongly agree }\end{array}$}} \\
\hline & & \\
\hline & - Marketing & $\square 1 \square 2 \square 3 \square 4 \square 5 \square 6 \square 7$ \\
\hline & - Quality & $\square 1 \square 2 \square 3 \square 4 \square 5 \square 6 \square 7$ \\
\hline & - Well-structured & $\square 1 \square 2 \square 3 \square 4 \square 5 \square 6 \square 7$ \\
\hline & - Feel at ease & 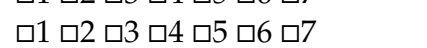 \\
\hline & - Original & $\square 1 \square 2 \square 3 \square 4 \square 5 \square 6 \square 7$ \\
\hline & - Beautiful & $\square 1 \square 2 \square 3 \square 4 \square 5 \square 6 \square 7$ \\
\hline & - Social & $\square 1 \square 2 \square 3 \square 4 \square 5 \square 6 \square 7$ \\
\hline & - Self & $\square 1 \square 2 \square 3 \square 4 \square 5 \square 6 \square 7$ \\
\hline & - Casual & $\square 1 \square 2 \square 3 \square 4 \square 5 \square 6 \square 7$ \\
\hline & - Unforgettable & $\square 1 \square 2 \square 3 \square 4 \square 5 \square 6 \square 7$ \\
\hline & - Humane & $\square 1 \square 2 \square 3 \square 4 \square 5 \square 6 \square 7$ \\
\hline & - Sincerely & $\square 1 \square 2 \square 3 \square 4 \square 5 \square 6 \square 7$ \\
\hline
\end{tabular}


Table A1. Cont.

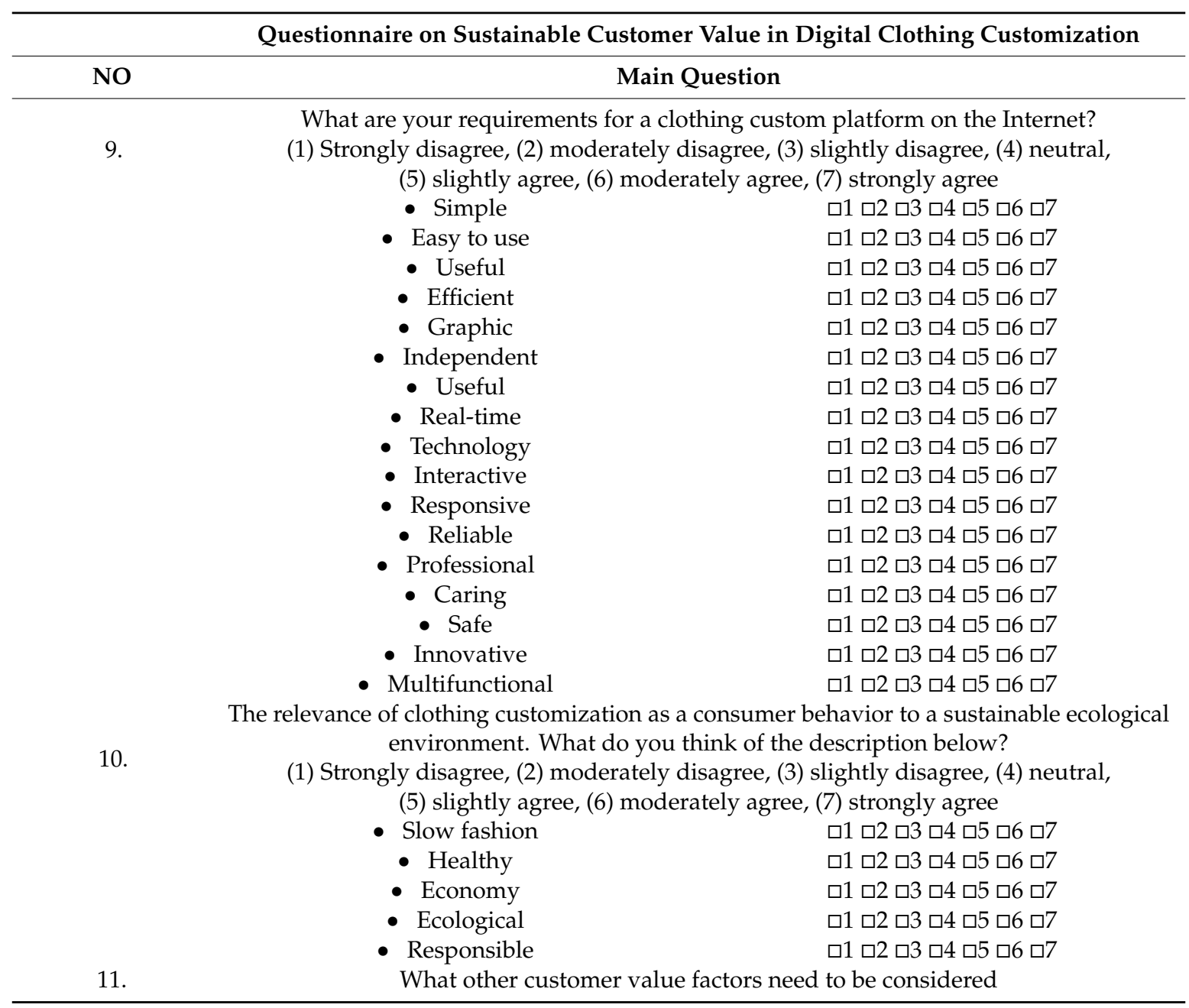

\section{References}

1. Gilmore, J.H.; Pine, B.J., II. The Experience Economy; Eco trend publications: Taibei, Taiwan, 2000; pp. $173-202$.

2. Victor, P. Design for the Real World; Academy Chicago Publishers: Chicago, IL, USA, 1985; p. 7.

3. Zhang, H.W.; Li, Q.Z.; Xu, S.Y. CiteSpace III-Based literature knowledge mapping of clothing digital technology in china. J. Zhejiang Sci.-Tech. Univ. 2016, 36, 354-360. [CrossRef]

4. Colombi, C.; Kim, P.; Wyatt, N. Fashion retailing "tech-gagement": Engagement fueled by new technology. Res. J. Text. Appar. 2018, 22, 390-406. [CrossRef]

5. Bertola, P.; Teunissen, J. Fashion 4.0. Innovating fashion industry through digital transformation. Res. J. Text. Appar. 2018, 22, 352-369. [CrossRef]

6. Larsson, J.K.J. Digital innovation for sustainable apparel systems Experiences based on projects in textile value chain development. Res. J. Text. Appar. 2018, 22, 370-389. [CrossRef]

7. Duchessi, P. Crafting Customer Value: The Art and Science; Purdue University Press: West Lafayette, IN, USA, 2002; pp. 12-124.

8. Kantamneni, S.P.; Coulson, K.R. Measuring Perceived Value: Scale Development and Research Findings from A Consumer Survey. J. Mark. Manag. 1996, 6, 72-86.

9. Smith, J.B.; Colgate, M. Customer value creation: A practical framework. J. Mark. Theory Pract. 2007, 15, 7-23. [CrossRef]

10. Sheth, J.N. Why we buy what we buy: A theory of consumption values. J. Bus. Res. 1991, 22, 159-170. [CrossRef]

11. Squire, B.; Brown, S.; Readman, J. The impact of mass customization on manufacturing trade-offs. Prod. Oper. Manag. 2006, 15, 10-21. [CrossRef] 
12. Wu, S.Z.; Su, J. C2C Online Shopping Evaluation System Based on Customer Perceived Value. J. Hebei North Univ. 2009, 25, 56-58.

13. Zhao, H.X.; Shan, L.J.; Liu, Y.F. Analysis of relationship marketing, perceived value and online shopping trust maintenance. J. Bohai Univ. 2013, 2, 190-196.

14. Peng, H. Research on the Impact of Customer Perceived Value on Brand Loyalty on Digital Intelligent Customization. Master's Thesis, Zhejiang Sci-Tech University, Hangzhou, China, 2016.

15. Li, H.; Zhu, W.M. Research on differences of customer perceived value about $\mathrm{O} 2 \mathrm{O}$ apparel customization brand. J. Silk 2015, 52, 36-41.

16. Zhu, W.M.; Wei, Y.H. Experiential value differences of clothing personalized customization under different situations. J. Text. Res. 2018, 39, 116-119.

17. Hong, Z.Y.; Zhu, W.M. Establishment of evaluation index system for clothing customization craftsman spirit value. J. Zhejiang Sci-Tech Univ. 2019, 42, 344-351.

18. Woodruff, R.B. Customer value: The next source for competitive advantage. J. Acad. Mark. Sci. 1997, 25, 139-153. [CrossRef]

19. Weigand, D.E. Customer Service Excellence: A Concise Guide for Libraries; American Library Association: Chicago, IL, USA, 1997.

20. Slater, S.F.; Narver, J.C. Market orientation, customer value, and superior performance. Bus. Horiz. 1994, 37, 22-28. [CrossRef]

21. Day, E.; Crask, M.R. Value assessment: The antecedent of customer satisfaction. J. Consum. Satisf. Dissatisfaction Complain. Behav. 2000, 19, 52-60.

22. Flint, D.J.; Woodruff, R.B.; Gardial, S.F. Customer value change in industrial marketing relationships: A call for new strategies and research. Ind. Mark. Manag. 1997, 26, 163-175. [CrossRef]

23. Flint, D.J.; Woodruff, R.B.; Gardial, S.F. Exploring the phenomenon of customers' desired value change in a business-to-business context. J. Mark. 2002, 66, 102-117. [CrossRef]

24. Parasuraman, A. Reflections on gaining competitive advantage through customer value. J. Acad. Mark. Sci. 1997, 25, 154. [CrossRef]

25. Rahman, O.; Fung, B.C.; Chen, Z. Young Chinese Consumers' Choice between Product-Related and Sustainable Cues-The Effects of Gender Differences and Consumer Innovativeness. Sustainability 2020, 12, 3818. [CrossRef]

26. Chen, Y.Y. Study on the Influencing Factors of Customers Choosing Online Apparel Customization. Master's Thesis, Harbin University of commerce, Harbin, China, 2018.

27. Sun, R.Z. Intelligent and customized development of China's clothing industry. Shanghai Text. Sci. Technol. 2017, 45, 63.

28. Yin, J. Research on the Value of Custom Garment Design in Contemporary China. Ph.D. Thesis, China Academy of Art, Hangzhou, China, 2018.

29. Pine, B.J., II; Korn, K.C. Infinite Possibility: Creating Customer Value on the Digital Frontier; China Machine Press: Beijing, China, 2012; p. 16.

30. Nielsen. The Quest for Convenience. Available online: https://www.nielsen.com/bh/en/insights/report/2018/ the-quest-for-convenience/ (accessed on 28 December 2019).

31. WGSN. The High Velocity Consumer. Available online: https://lp.wgsn.com/high-velocity-wp.html (accessed on 28 December 2019).

32. PwC. Back to the Core: Revigorate Experience-Driven Retail at a Time of Uncertainty. Available online: https:// www.pwccn.com/en/retail-and-consumer/global-consumer-insights-survey-2019-china-report.pdf (accessed on 28 December 2019).

33. Boston Consulting Group. Available online: http://image-src.bcg.com/Images/BCG-Five-Profiles-ThatExplain-Chinas-Consumer-Economy-June-2017-CHN_tcm55-163226.pdf (accessed on 28 December 2019).

34. Global Fashion Agenda. Pulse of the Fashion Industry 2019 Update. Available online: https://www. globalfashionagenda.com/pulse-2019-update/ (accessed on 28 December 2019).

35. Salesforce Research. State of the Connected Customer, 3rd ed. Available online: https://c1.sfdcstatic.com/ content/dam/web/en_us/www/assets/pdf/salesforce-state-of-the-connected-customer-report-2019.pdf (accessed on 28 December 2019).

36. China International Electronic Commerce Center (CIECC). Available online: http://images.mofcom.gov.cn/ 1tfzs/201909/20190920083807922.pdf (accessed on 28 December 2019). 
37. iResearch. Available online: http://report.iresearch.cn/wx/report.aspx?id=3367 (accessed on 28 December 2019).

38. PwC. Total Retail 2017: 10 Retailers Investments for an Uncertain Future. Available online: https://www.pwc. com/gx/en/industries/assets/total-retail-2017.pdf (accessed on 28 December 2019).

39. Davis, F.D. A Technology Acceptance Model for Empirically Testing New End-User Information Systems. Ph.D. Thesis, Wayne State University, Detroit, MI, USA, 1980.

40. Oliver, R.L. A Cognitive Model of the Antecedents and Consequences of Satisfaction Decisions. J. Mark. Res. 1980, 17, 460. [CrossRef]

41. Goffman, E. The Presentation of Self in Everyday Life; Doubleday: New York, NY, USA, 1959.

42. Julier, G. The Culture of Design; Sage Publications: London, UK, 2008; pp. 3-6.

43. Parasuraman, A.; Zeithaml, V.A.; Berry, L.L. A Conceptual Model of Service Quality and Its Implications for Future Research. J. Mark. 1985, 49, 41-50. [CrossRef]

44. Throsby, D. Economics and Culture; Cambridge University Press: Cambridge, MA, USA, 2001; pp. $25-37$.

45. Kaynama, A.K.; Black, C.I. Proposal to assess the service quality of online travel agencies: An exploratory study. J. Prof. Serv. Mark. 2000, 21, 63-88.

46. Donthu, N.; Yoo, B. Developing a scale to measure the perceived quality of an internet shopping site (SITEQUAL). Q. J. Electron. Commer. 2001, 2, 38.

47. Zeitham, A.; Parasuraman, A.; Malhotra, A. Service Quality Delivery Through Web Sites: A Critical Review of Extant Knowledge. J. Mark. 2002, 30, 358-371.

48. Gorsuch, R.L. Factor Analysis, 2nd ed.; Lawrence Erlbaum Associates: Hillsdale, MI, USA, 1983.

49. Chiou, H.J. Quantitative Research and Statistical Analysis in Social E Behavioral Sciences, 3rd ed.; Wu Nan Books: Taipei, Taiwan, 2010; ISBN 9789571188911.

50. Sun, C.L. Construction and Application of an Indicator SYSTEM for Compulsory Education. Ph.D. Thesis, National Chengchi University, Taipei, Taiwan, 1998, unpublished.

51. Wang, K.M.; Wu, H.T.; Wu, M.L. The reconstruction of evaluation indicators for elementary schools in Kaohsiung city. J. Educ. Adm. Eval. 2008, 5, 75-106, (In Chinese semantic translation).

52. Li, W.T.; Ho, M.C.; Yang, C. Study on Design Strategy for Sustainable Development of Chinese Solar Term Culture. Sustainability 2018, 10, 4355. [CrossRef]

53. Thorstein, V. The Theory of the Leisure Class: An Economic Study in the Evolution of Institutions; Macmillan: New York, NY, USA, 1899.

54. Sturken, M.; Cartwright, L. Practices of Looking: An Introduction to Visual Culture, 2nd ed.; Oxford University Press: New York, NY, USA, 2009; p. 291.

55. Nakai, H. Zero Inventory Sales Operation Strategy; Tsinghua Management Science Book Center: Taibei, Taiwan, 1991; p. 25, (In Chinese semantic translation).

56. Gilmore, J.H.; Pine, B.J., II. Authenticity: What Consumers really Want; Harvard Business School Press: Brighton, MA, USA, 2007; p. 25.

57. Dominique, D. La Consummation; Presses Universitaires de France: Paris, France, 2006; p. 48.

58. Prahalad, C.K.; Ramaswamy, V. Co-creation experiences: The next practice in value creation. J. Interact. Mark. 2004, 3, 5-14. [CrossRef]

(C) 2020 by the authors. Licensee MDPI, Basel, Switzerland. This article is an open access article distributed under the terms and conditions of the Creative Commons Attribution (CC BY) license (http://creativecommons.org/licenses/by/4.0/). 